\title{
Poemas inéditos del Vihuelista y eSCRitor Luis Milán y Nuevas CONSIDERACIONES SOBRE SU IDENTIDAD: EL MS. 2050 DE LA BIBLIOTECA DE CATALUNY* ${ }^{*}$
}

\author{
UnPublished Poems of the VihUelist and Writer Luis Milán and NeW \\ Considerations about his Identity: the MS 2050 of the Biblioteca \\ de Catalunya
}

Francesc Villanueva Serrano

Universitat Politècnica de València

\section{Resumen:}

En el ms. 2050 de la Biblioteca de Catalunya se conserva, bajo el título de Proçeso de coplas de burlas que pasaron entre don Luis del Milán, el músico, y don Joan Fernández, el conjunto de poesías más completo de la conocida disputa que mantuvo el vihuelista y escritor Luis Milán con el poeta Juan Fernández de Heredia. Sin embargo, esta fuente no ha sido considerada en las ediciones existentes y, como consecuencia, bastantes de las composiciones permanecen todavía inéditas. A partir de la información que transmiten algunos de estos textos poéticos y, especialmente, de las interesantes rúbricas que los preceden, se trata en detalle la cuestión de la identidad de Milán. La principal conclusión que puede extraerse es la necesidad de considerar la revisión de la identificación del autor con Lluís del Milà i Eixarch, ampliamente admitida en la actualidad. En apéndice se ofrece una edición anotada del Proceso.

\section{Palabras clave:} Valencia.

Luis Milán; Juan Fernández de Heredia; vihuelista; escritor; Proceso de coplas de burlas; El Cortesano; duques de Calabria;

\section{Abstract:}

In the MS 2050 of the Library of Catalunya is preserved, under the title of Proçeso de coplas de burlas que pasaron entre don Luis del Milán, el músico, y don Joan Fernández, the most complete set of poems of the known dispute between the vihuelist and writer Luis Milán and the poet Juan Fernández de Heredia. However, this source hasn't been considered in the editions of the works of both authors and, as a result, plenty of the compositions are still unpublished. From the texts of some of these poems and their interesting headings, the question of the identity of Milán is discussed in detail here. The main conclusion is the need of

* Quisiera dejar constancia de mi agradecimiento a Antonio Ezquerro Esteban, director de mi tesis doctoral, por su amabilidad al realizar una lectura crítica previa de este trabajo y por sus valiosas sugerencias. 
considering the revision of the identification of this author with Lluís del Milà i Eixarch, that is nowadays widely accepted. As an appendix to this article, an annotated edition of the Proceso is offered.

\section{Key Words:} Valencia.

Luis Milán; Juan Fernández de Heredia; vihuelist; writer; Proceso de coplas de burlas; El Cortesano; Dukes of Calabria;

\section{INTRODUCCIÓN}

El día 28 de noviembre de 1526 hicieron su entrada solemne en la ciudad de Valencia el duque de Calabria don Fernando de Aragón (*Andria, 1488; †Valencia, 1550) y la que había sido reina de Aragón Germana de Foix (*Mezières, 1488; †Llíria, 1536)ํㅜㄹ quienes poco tiempo antes habían contraído matrimonio y recibido, simul et in solidum y con carácter vitalicio, el nombramiento de virreyes en el reino de Valencia. Las nuevas autoridades se instalaron en el palacio del Real, situado extramuros al norte de la ciudad, que desde antiguo era la residencia de los reyes de Aragón en sus estancias en la capital valenciana. La llegada de tan ilustres y poderosos personajes abrió un período de gran fecundidad cultural en el entorno del palacio, que el duque mantuvo tras el fallecimiento de Germana de Foix (1536) y su segundo matrimonio (1541) con doña Mencía de Mendoza (*Jadraque, 1508; †Valencia, 1554). Durante un cuarto de siglo, la corte del duque y sus consortes fue escenario de la actividad creativa de humanistas, músicos y escritores ${ }^{2}$.

Poesía, música y representaciones teatrales, intercaladas entre diálogos jocosos, parece ser que fueron los principales ingredientes de muchas de las reuniones de la alta sociedad vividas en el Real. Junto a servidores del duque -como los bufones, las criadas o los músicos de su capilla- un gran número de caballeros y damas de la nobleza asistían a estas animadas veladas, que quedaron reflejadas, con cierta dosis de ficción, en el libro titulado El Cortesano (Valencia: Joan d'Arcos, 1561), escrito por uno de los tertulianos habituales, el noble vihuelista y escritor don Luis Milán³ . A lo largo de la obra se pone claramente de ma-

1 Germana de Foix fue la segunda y última esposa de Fernando el Católico, rey de Aragón (1479-1516), cuyo matrimonio tuvo lugar en 1505. A pesar de que tras la muerte de Fernando dejó de reinar, en su entorno siguió recibiendo el tratamiento de "reina" hasta el fin de sus días.

2 Como síntesis actualizada de la abundante bibliografía existente sobre aquella actividad cultural puede consultarse FERRER VALLS, Teresa: “Corte virreinal, humanismo y cultura nobiliaria en la Valencia del siglo XvI”, en E. Berenguer (coord.), Reino y ciudad. Valencia en su historia. Madrid, Fundación Caja Madrid, 2007, pp. 185-200.

3 El Cortesano de Milán guarda evidentes paralelismos con Il Cortegiano (Venecia: Aldo Romano y Andrea d'Asola, 1528 ) de Baldassare Castiglione (*Casatico, Mantua, 1478; †Toledo, 1529), un famoso tratado sobre las cualidades que debía poseer el perfecto hombre de corte. De la obra de Milán existe una edición del siglo xix [Milán, Luis: El Cortesano. Libro de motes de damas y caballeros. Madrid, Aribau y C $\left.\mathrm{C}^{\mathrm{a}}, 1874\right]$, otra acompañada de un estudio introductorio y el facsímil [ID.: El Cortesano, ed. de Vicent Josep Escartí, 2 vols. Valencia, Biblioteca Valenciana, 2001] y una más reciente [ID.: El Cortesano, ed. de Vicent Josep Escartí. Valencia, Institució Alfons el magnànim, Diputació de València, 2010]. Otra obra impresa de Luis MiLÁN es el Libro de motes de damas y cavallero: intitulada juego de mandar, Valencia, Francisco Díaz Romano, 1535, de la que existe una edición del siglo XIX [ID.: El Cortesano. Libro de motes..., op. cit.], dos facsímiles [ID.: Libro de Motes de Damas y Caballeros en la Corte valenciana de la Reina Doña Germana. Valencia, Librerías París-Valencia, 1982; ID.: Libro de motes de damas y caualleros: inti- 
nifiesto la rivalidad dialéctica, en tono burlesco, que existió entre Milán y don Juan Fernández de Heredia, señor de Andilla ${ }^{4}$, cuya máxima expresión en el lenguaje poético se alcanza en el Proceso de coplas de burlas. A partir de algunas de sus composiciones trataré en este trabajo ciertos aspectos fundamentalmente relacionados con la identidad del vihuelista ${ }^{5}$.

\section{EL PROCESO DE COPLAS DE BURLAS QUE PASARON ENTRE DON LUIS DEL MILÁN, EL MÚSICO, Y DON JOAN FERNÁNDEZ}

\section{LAS FUENTES}

En 1562 veía la luz el libro titulado Las obras de don Joan Fernández de Heredia, assí temporales, como espirituales, impreso en los talleres valencianos de Joan Mey6 . El promotor de esta iniciativa editorial fue su hijo natural Llorenç Ferrandis d'Herèdia, quien decidió llevar a la imprenta las obras de su

tulado el juego de mandar. Valencia, Vicent García, 2005], dos ediciones con facsímil [ID.: Libro de motes de damas y caballeros, estudio de Justo García Morales. Barcelona, Torculum, 1951; ID.: Libro de motes de damas y caballeros (Valencia, 1535), ed. de Alberto Noguera, http://parnaseo.uv.es/lemir/Textos/Motes/index.html (última consulta: julio de 2010)] y una edición crítica reciente acompañada de un estudio [ID.: El libro de motes de damas y caballeros de Luis de Milán: Edición crítica y estudio, ed. de Isabel Vega Vázquez. Santiago de Compostela, Universidade de Santiago de Compostela, 2006]. Por lo que respecta a su faceta vihuelística, Milán es el autor de la trascendental obra titulada El Maestro. (Valencia, Francisco Díaz Romano, 1536), el primer libro de vihuela impreso en España, del cual existen diversas ediciones modernas y en facsímil. Para una relación actualizada de éstas, véase Milán, Luis: Libro de música de vihuela de mano intitulado 'El maestro', ed. facsímil de Francisco Roa, estudio de Gerardo Arriaga. Madrid, Sociedad de la Vihuela, 2008, pp. XXII-XXIII. Era habitual en la Valencia de la época que las personas de relevancia social como los nobles, altos funcionarios o artistas de prestigio castellanizaran en ciertos contextos no sólo su nombre de pila, sino también su apellido. En cambio, en otros ámbitos, como el administrativo, suelen aparecer en su forma valenciana. A lo largo de este trabajo hemos optado por usar la forma castellanizada para los autores que se han hecho conocidos de esta manera a través de sus obras, como son los casos de Luis Milán y Juan Fernández de Heredia. Para el resto de personajes valencianos que aparecen en este trabajo se emplea la forma valenciana original. En el caso de Milán puede comprobarse que la forma valenciana del apellido, sin duda alguna, era Milà, tal como le llama Jerònima Beneyto, esposa de Fernández de Heredia, hablando en valenciano/catalán en El Cortesano: “- Don Loýs Milà: llançau de ací aquest porch espí o feu-lo callar a mots, que sols vos lo emboçau quant los dos vos motejau.” (trad.: “- Don Luis Milán: lanzad de aquí este puerco espín o hacedlo callar a motes, que sólo vos lo embozáis cuando los dos os motejáis”) [Milán, Luis: El Cortesano, ed. de Vicent Josep Escartí, vol. 1, op. cit., p. 498]; “- Don Luýs Milà: feu del resto, que com a guant lo m'adobau, que no put a mal marit, quant los dos vos coblejau” (trad.: “- Don Luis Milán: haced del resto, que como guante me lo adobáis, que no put [?] a mal marido, cuando los dos os copleáis") [Ibid., p. 652]. Por su parte, el bufón Gilot alude así en valenciano/catalán al competidor de Milán: "No u dich perquè Sa Excel·lencia y Joan Ferrandiz o sien, encara que may han fet parir a ses mullers." (trad.: "No lo digo porque Su Excelencia y Juan Fernández lo sean, aunque nunca han hecho parir a sus mujeres") [Ibid., p. 240].

4 Don Juan Fernández de Heredia y Díez de Calatayud (*Valencia, 1482-3; †Valencia, 1549) fue uno de los cuatro hijos varones de los señores de Andilla. Casó con doña Jerònima Beneyto i Carroç Pardo de la Casta, seguramente en 1510, con quien no tuvo descendencia. Durante la Guerra de las Germanías, participó activamente y con éxito en el bando real. [MARTí GRAJALES, Francisco y José María PUIG TorRaLVA: Estudio histórico-crítico de los poetas valencianos de los siglos XVI, XVII y XVIII. Valencia, Viuda de Ayoldi, 1883].

5 El mismo Proceso, conjuntamente con el segundo prólogo de La Vesita de Fernández de Heredia (1541) y especialmente con El Cortesano, ya ha sido objeto de otro estudio, centrado en esa ocasión en la caracterización de los personajes a través del elemento ficcional [SÁnchez PALACios, Esmeralda: "Lluís del Milà i Joan Fernàndez d'Heredia a la cort dels ducs de Calàbria (València 1526-1550)", en Miscel-lània homenatge a Rafael Martí de Viciana en el v centenari del seu naixement $1502-2002$. Vila-Real, Ajuntament de Burriana, Biblioteca Valenciana, 2003, pp. 435-458].

6 Para conocer detalladamente las fuentes de las obras de Fernández de Heredia, pueden consultarse: Martí Grajales, Francisco y José María Puig Torralva: op. cit., pp. 221-226; Jauralde García, Pablo: "Fernández de Heredia, Juan", en Pablo Jauralde Pou (ed.), Diccionario filológico de literatura española del siglo XVI. Madrid, Editorial Castalia, 2009, pp. 376-383. 
padre ya fallecido. La publicación, que recoge la mayor parte de las obras conocidas del autor, incluye entre los ff. 149r-169v un curioso conjunto de poemas satíricos que Fernández de Heredia y Milán se dirigieron mutuamente, encabezados por una rúbrica cuyo comienzo es "Algunas obras de burlas". Este grupo de composiciones poéticas ha tenido difusión en dos ediciones modernas del impreso, datadas en 1913 y 1955, gracias a las cuales son hoy accesibles al lector interesado7.

No obstante, el conjunto de poemas conservado más completo de este coloquio de burlas no se encuentra en el impreso de 1562 sino en el ms. 2050 de la Biblioteca de Catalunya, procedente de la colección de Arturo Sedó, a pesar de lo cual no se tuvo en cuenta en ninguna de las dos ediciones modernas del mencionado libro ${ }^{8}$. Su conservación en manos privadas hasta el año 1969 ha debido influir en el hecho de que no haya sido estudiado en profundidad y en su conjunto'. En el f. 1r, a modo de portada, puede leerse: "Las obras del egregio cavallero y excelente poeta don Joan Fernández d'Eredia, señor de la baronía de Andilla, con suma diligencia copiladas, corregidas y puestas en horden. 1555". El grupo de poemas que aquí tratamos se encuentra entre los ff. 119r-146v, encabezados por una introducción que comienza por "Aquí se contiene un proçeso de coplas de burlas que pasaron entre don Luis del Milán, el músico, y don Joan Fernández [...]”, de donde tomamos el nombre abreviado de Proceso de coplas de burlas o, simplemente Proceso, que aplicaremos de aquí en adelante a este conjunto poético. Presenta diversas características que lo convierten en la fuente más interesante de esta disputa, por lo que se ha denominado fuente $A$ en este trabajo:

1. Su datación es la más antigua (1555) y, por tanto, la más próxima a la época de la corte del duque de Calabria (†1550), personaje que está presente en algunas de las composiciones. Si a ello se añade su probable origen valenciano, atribuido por Josep Romeu ${ }^{10}$, se justifica la "grandísima autoridad" que le otorga Joaquín Montaner ${ }^{11}$.

2. Es la que contiene mayor número de poemas de este ciclo, treinta y siete, una parte de los cuales permanecen inéditos, especialmente del grupo que se atribuye a Milán.

3. Los poemas presentan una ordenación más coherente que en el resto de fuentes ${ }^{12}$.

7 Fernández de Heredia, Juan: Obras de D. Juan Fernández de Heredia, poeta valenciano del siglo xvi, ed. de Francisco Martí Grajales. Valencia, Manuel Pau, 1913; ID.: Obras, ed. de Rafael Ferreres. Madrid, Espasa-Calpe, 1955.

8 Una descripción de este manuscrito puede encontrarse en MonTAnER, Joaquín: La colección teatral de don Arturo Sedó. Barcelona, Seix y Barral Hnos., 1951, p. 90. Otra descripción más actualizada del manuscrito y de su contenido detallado en DuRAN, Eulàlia (ed.): Repertori de manuscrits catalans (1474-1620), vol. 1. Barcelona, Institut d'Estudis Catalans, 1998, pp. 298-308.

9 No obstante, se han realizado trabajos que han tenido en cuenta parte de su contenido, ofreciendo transcripciones completas o parciales de algunos de los poemas. Vid. Schmid, Beatrice: "Les poesies en català de Joan Ferrandis d'Herèdia", en Elvezio Canonica de Rochenmonteix y Ernst Rudin (coords.), Literatura y bilingüismo: Homenaje a Pere Ramírez. Kassel, Reichenberger, 1993, pp. 29-41; SÁNCHEZ PALACIOS, Esmeralda: op. cit.

10 Romeu, Josep: Teatre profà, vol. I. Barcelona, Editorial Barcino, 1962, p. 63. Al principio del Proceso (f. 199r) se indica: "Y más se a de notar qu'en el discurso d'este proceso se tocan muchas cosas que son al estilo y modo de hablar y tratar valenciano, por lo qual se requiere entendello para que se goze, en espeçial los que son mal pláticos en las cosas de Valençia. Y para que se advier<ta> se señala en la margen con este señal : ". Ese conocimiento de las peculiaridades valencianas del recopilador parece apoyar la idea de Romeu.

11 Montaner, Joaquín: op. cit., p. 90.

12 En este aspecto, es interesante observar que en el poema ${ }^{\circ} 35$, situado prácticamente al final del Proceso, en que se recapitula sobre lo anterior, se hace alusión al coloquio que "Milán desparó primero" y que fue traído por Pujades, es decir al poema $\mathrm{n}^{\circ} 1$. En cambio, en las otras fuentes esta composición no se encuentra al principio sino hacia el final del conjunto de poemas. Así pues, el texto del poema ${ }^{\circ} 35$ es coherente en $A$ mientras que no lo es en el resto de fuentes que lo contienen. 
4. Algunas de las composiciones presentan una mayor extensión que en el resto de fuentes.

5. Las rúbricas de los poemas son más prolijas y proporcionan mayor información sobre el contexto creativo de las poesías ${ }^{13}$.

6. Existen frecuentes variantes textuales respecto a la versión difundida del impreso de 1562.

7. Es la única fuente de la que no existe una edición integral publicada de los poemas de esta disputa, ni ha sido tenida en cuenta en las ediciones del resto.

El impreso mencionado de 1562 con las obras de Fernández de Heredia es la segunda fuente en cuanto a presencia de poemas contenidos en el Proceso - veintidós completos y tres incompletos ${ }^{14}$ - por lo que se ha denominado $B$. Sus rúbricas son mucho más escuetas que las de $A$ y aportan escasos datos o aclaraciones adicionales. Ofrece un único poema, de Fernández de Heredia, que no está presente en $A^{15}$.

El ms. 2621 de la Biblioteca Nacional de España, al que aquí se ha denominado $C$, fundamentalmente contiene poesías de Fernández de Heredia, aunque también de otros autores de la época ${ }^{16}$. Sólo incluye diez poemas completos y dos incompletos del Proceso, que se encuentran en los ff. $154 \mathrm{v}-169 \mathrm{v}$, de los que existe una edición del siglo XIX en cuya introducción se señala que el manuscrito perteneció a Serafín Estébanez Calderón $(* 1799 ; \dagger 1867)^{17}$. Todas las poesías que en estos folios se contienen son de Fernández y existen en $A$ y $B$. Sus rúbricas son diferentes a las de estas dos fuentes sin que, a pesar de ello, añadan información adicional relevante. Los poemas presentan una destacable afinidad textual con $B$ aunque no total, por lo que no parece prudente pensar en que $C$ proceda de ninguno de los anteriores.

Por último, el propio impreso de El Cortesano incluye, en la jornada primera, cuatro poemas de Milán contra Fernández presentes en el Proceso, con las correspondientes respuestas atribuidas a éste -tres de ellas totalmente diferentes a las existentes en $A$ y $B$-. Estos poemas están insertos entre diálogos que, en alguna ocasión, nos revelan detalles de las anécdotas o sucesos que dieron pie a su composición. Nos referiremos a ésta como fuente $D$.

La tabla 1 refleja los poemas contenidos en el Proceso, numerados en el orden en que aparecen, señalando aquéllos que existen en el resto de fuentes.

13 El interés que despierta este hecho ya ha sido reseñado en ScHMID, Beatrice: op. cit., p. 32. de ellos.

14 Se ha considerado un poema completo si contiene todos los versos de la versión de $A$ e incompleto si carece de alguno

15 Se trata del que comienza "Tan fuera, como vos dentro" [Fernández de Heredia, Juan: Obras, ed. de Rafael Ferreres, op. cit., pp.185-186].

16 Según el catálogo de manuscritos de la Biblioteca Nacional, en la $3^{\mathrm{a}}$ hoja de guarda puede leerse: "En este libro ay poesías de Jorge Montemayor, de Juan Fernández, de don Luis Margarit, de don Luis de Milán y de don Diego Hurtado de Mendoza". Posteriormente se han tachado los nombres de Margarit y de Milán y se ha añadido: "de N. Torrellas, de don Hernando de Acuña, de Álvaro Gómez de Ciudad Real y de otros autores inciertos". La descripción y contenido detallado de este manuscrito pueden consultarse en: Biblioteca Nacional de España: Inventario general de manuscritos de la Biblioteca Nacional, viII. Madrid, Ministerio de Educación Nacional, Dirección General de archivos y bibliotecas, 1965, pp. 114-123; JAURALDE Pou, Pablo y Manuel Sánchez Mariana (dirs.): Catálogo de manuscritos poéticos castellanos de los siglos XVI y XVII en la Biblioteca Nacional, I. Madrid, Ministerio de Cultura, Biblioteca Nacional, 1993, pp. 291-302; JAuralde Pou, Pablo (dir.): Catálogo de manuscritos de la Biblioteca Nacional con poesía en castellano de los siglos XVI y XVII, vol. I. Madrid, Editorial Arco/Libros, 1998, pp. $239-247$.

17 Paz y Meliá, A.: "Coplas de Juan Fernández contra don Luis de Milán”, Revista de Archivos, Bibliotecas y Museos, 15 (5 de agosto de 1876), pp. 258-262; Ibid., 16 (20 de agosto de 1876), pp. 275-278. 


\begin{tabular}{|c|c|c|c|c|c|}
\hline$n^{0}$ & Primer verso & Autor & $B$ & $C$ & $D$ \\
\hline 1 & Señor, salió de la cueva & Milán & च & & \\
\hline 2 & Como esto toque a mí & Fernández & घ & & \\
\hline 3 & Nunca vi mejor empresa & Milán & [ & & [ \\
\hline 4 & Esas coplas que hazéys & Fernández & घ & ש & \\
\hline 5 & Don Joan, Turcas maneras & Milán & घ & & \\
\hline 6 & Dar de san Martín razón & Fernández & ם & घ & \\
\hline 7 & Vuestro ayre no me miente & Milán & $\square$ & & \\
\hline 8 & Tres damas estotro día & Fernández & $\square$ & [ & \\
\hline 9 & Las que no corrido me an & Milán & [ & & \\
\hline 10 & No negar fuera mejor & Fernández & घ & $\square$ & \\
\hline 11 & En la cuenta estoy, señor & Milán & 口 & & \\
\hline 12 & No me diréys aunque os toca & Fernández & घ & घ & \\
\hline 13 & Engañamundo, señor & Milán & $\square$ & & \\
\hline 14 & Soys el mayor trobador & Fernández & घ & घ & \\
\hline 15 & Dezí, señor, no's corréys & Milán & & & \\
\hline 16 & No gastéys más coplas mías & Fernández & घ & घ & \\
\hline 17 & No's paresca cosa nueva & Milán & & & \\
\hline 18 & Estas coplas que me dan & Fernández & ם & घ & \\
\hline 19 & No quiero caer ni cayo & Milán & ם & & \\
\hline 20 & Quien mi çetrería siente & Fernández & घ & $\square$ & \\
\hline 21 & Señor, ut, re, mi, fa, sol & Milán & 口 & & $\mathbf{\square}$ \\
\hline 22 & Señor don Luis Ferrer & Fernández & [ & घ & \\
\hline 23 & Dicho me an, señor don Joan & Milán & घ & & घ \\
\hline 24 & Por la risa y gran plazer & Fernández & [ & घ & \\
\hline 25 & Una ropa avéys sacado & Milán & घ & & \\
\hline 26 & Muchos están aburridos & Fernández & & & \\
\hline 27 & Donosa está vuestra fama & Milán & & & [ \\
\hline 28 & Sienpre en achaque de trama & Fernández & & & \\
\hline 29 & Liriano, liriano & Milán & [ & & \\
\hline 30 & O qué lirio tan donoso & Fernández & & & \\
\hline 31 & D'esta vez yo me arisco & Milán & & & \\
\hline 32 & Muero por desengañaros & Fernández & & & \\
\hline 33 & De la carta plazer huve & Milán & & & \\
\hline 34 & Vuesa merçed se aperçiba & Fernández & & & \\
\hline 35 & $\mathrm{Si}$ el buen consejo aprovecha & Fernández & घ & घ & \\
\hline 36 & Lo que de vos me lastima & Fernández & & & \\
\hline 37 & Dos Ponçes, y no Pilatos & Milán & & & \\
\hline
\end{tabular}

Poema completo (respecto a la versión de $A$ ) $\quad \square$ Poema incompleto (respecto a la versión de $A$ )

Tabla 1. Los poemas del Proceso de coplas de burlas y sus otras fuentes

Por todos los motivos reseñados, se ha considerado de interés el ofrecer al lector interesado una edición completa del Proceso según A, sin olvidar el resto de fuentes localizadas que transmiten sus poemas, que se incluye en un apéndice a este trabajo. Se ha de puntualizar que no se ha pretendido realizar una edición crítica con rigor filológico, aunque sí reflejar el texto completo de estas composiciones señalando las variantes semánticas más significativas de las otras fuentes, al tiempo que ofreciendo notas a pie de página para su mejor comprensión. 


\section{El Proceso de coplas de burlas en el ambiente de la corte del duque de Calabria}

En la epístola dedicatoria a Felipe in de El Cortesano, el autor señala que su libro contiene "conversaciones para saber burlar a modo de palacio"18. En efecto, el carácter burlesco e ingenioso es una constante en las intervenciones, en poesía o en prosa, de todos los personajes que frecuentan o desfilan puntualmente por las reuniones del duque de Calabria y la reina Germana recreadas en este libro. Y no sólo eso, sino que en no pocas ocasiones se teoriza sobre el concepto de burla, tratando sobre sus características, sus propiedades o la adecuación de su uso. Hablando sobre las cualidades verbales del buen cortesano Luis Milán afirma:

Y si [el cortesano] viene a burlar en conversación, jugar del vocablo da buen son a los muy buenos oýdos, que nunca serán reýdos y podrán hazer reýr, que agudeza muy graciosa apenas es enojosa [...] Y algunas vezes en burlar, prosa y verso debe hablar. Y debaxo sta alegría no calle philosophía muy de veras, que las burlas haze veras. ${ }^{19}$

Por tanto, el vihuelista consideraba que el cortesano ideal debía de poseer un fino ingenio para las burlas en la conversación, tanto en prosa como en verso, que le permitiera decir verdades, incluso molestas, sin enfadar ni ofender a su interlocutor. Juan Fernández incide en la apreciación al señalar que "las burlas sin dañar, nunca obligan a enojar" ${ }^{20}$. Este planteamiento está perfectamente reflejado en el libro, donde los personajes hablan frecuentemente en lenguaje burlesco de sus defectos físicos o de cuestiones espinosas de su intimidad, tales como infidelidades o situaciones embarazosas acontecidas. Una intervención del duque de Calabria añade la necesidad de la brevedad al opinar que "las burlas no deven ser largas, aunque sean buenas, que si turan mucho pueden hazer mal estómago, por ser de mala digestión el burlar; y si son pocas puédense digerir" ${ }^{21}$. Cuando las burlas en verso eran consideradas "mentirosas y de baxo estilo" recibían la denominación de "pullas"22.

El Cortesano también nos ofrece algunas claves sobre el contexto en que los poemas del Proceso de coplas de burlas pudieron crearse o, al menos, escucharse. En la jornada primera, durante una cacería, don Berenguer Aguilar recuerda el tiempo en que Juan Fernández "se yva de cámaras de baxas coplas que contra don Luys Milán trobó”. Luis Milán propone entonces al duque de Calabria que sea el juez para dirimir "si fueron coplones lo que respondió a mis coplas" su "competidor" Juan Fernández, propuesta que inmediatamente es aceptada por don Fernando, aunque pospuesta para otro momento más adecuado ${ }^{23}$. Tras la comida en Llíria, el duque sentencia: "Yo prometí ser juez para juzgar quál de los dos, o Joan Fernández o don Luys Milán. Agora podéys dezir las coplas que os hezistes, que oýdas las dos partes, yo diré mi parescer”. Comienza entonces Luis Milán a recitar, ante el noble auditorio asistente, poesías burlescas contra Juan Fernández hasta un número de seis, que son contestadas una a una por éste. El

18 Milán, Luis: El Cortesano, ed. de Vicent Josep Escartí, vol. 1, op. cit., p. 178.

19 Ibid., pp. 255-256.

20 Ibid., p. 222.

21 Ibid., p. 232.

22 Ibid., p. 224.

23 Ibid., p. 199. El apelativo "competidor" es usado por el duque Ibid., p. 357. 
mismo Fernández es, además, objetivo de sendas poesías del mismo género lanzadas por Dídac Lladró y Francesc Fenollet, aliados de Milán, a las que igualmente responde. Tras esta serie de composiciones, sólo interrumpida en alguna ocasión por alguno de los oponentes para ofrecer detalles en prosa del suceso supuestamente real en que se basa el siguiente poema, el duque sentencia: "Yo doy por tan buenas vuestras coplas que no sé a quién dar la mejoría, después que se ha mejorado Joan Fernández en rasgar las malas coplas que por mal consejo hizo contra don Luys Milán"24. Un poco más adelante se reaviva brevemente el enfrentamiento -un solo poema de Milán y la correspondiente respuesta de Fernández-, cuya posible continuidad es cortada en seco por el duque ${ }^{25}$.

Así pues, con las debidas precauciones que aconseja la consideración de una obra con cierto componente ficticio como El Cortesano ${ }^{26}$, parece lógico pensar que las poesías del Proceso de coplas de burlas pudieron haber sido recitadas públicamente por sus autores en veladas cortesanas, a modo de desafío, con el fin de demostrar ante un auditorio cultivado las cualidades poéticas y el ingenio de los rivales. En el mundo nobiliario de la época, estamento militar por excelencia, se practicaban diversos entretenimientos en tiempos de paz que, en el fondo, estaban imitando a las contiendas, tales como justas, torneos o juegos de cañas y, en el campo literario, justas poéticas o certámenes. El propio término "proceso" que define a esta disputa, con la existencia incluso de un abogado defensor de Fernández, Martí Ponç, lleva en este caso ficticiamente al campo de batalla judicial el conflicto entre los dos poetas ${ }^{27}$.

A partir de este pasaje de El Cortesano, también se puede inferir la existencia de unas respuestas iniciales de Fernández a los poemas de Milán no incluidas en este libro -las "baxas coplas" de las que habla don Berenguer- las cuales son, en opinión del duque, mejoradas por otras diferentes que se recitan ante él y cuyo texto sí aparece en el impreso. Si recordamos que la mayor parte de las contestaciones de Fernández que aparecen en el Proceso -coincidentes además con las de $B$ y $C$ - son distintas a las que este mismo personaje recita en El Cortesano para contrarrestar las mismas poesías de Milán, podemos sospechar que las primeras fuesen las primigenias ${ }^{28}$.

24 Ibid., pp. 221-232.

25 Ibid., pp. 236-237.

26 Sobre el carácter de ficción de la obra puede consultarse: CRUïLles, Marqués de: Noticias y documentos relativos a doña Germana de Foix, última reina de Aragón, ed. de Ernest BelEnguer. Valencia, Universitat de València, 2007, p. 406, nota 25; Solervicens i Bo, Josep: El diàleg renaixentista: Joan Lluís Vives, Cristòfor Despuig, Lluís del Milà, Antoni Agustí. Barcelona: Publicacions de l'Abadia de Montserrat, 1997, pp. 174-180; SÁnchez PALACIOs, Esmeralda: "L'ideal de cortesà: les facècies de Lluís del Milà a la cort dels ducs de Calàbria", en Actes dels I, II i III col-loquis sobre art i cultura a l'època del Renaixement a la Corona d'Aragó. Tortosa 1996-1999. Tortosa: Generalitat de Catalunya, 2000, pp. 345-354; ID.: "Lluís del Milà i Joan Fernàndez d'Heredia...", op. cit., pp. 435-456.

27 Este aspecto es particularmente explícito en el poema $\mathrm{n}^{\circ} 35$.

28 Esta posibilidad ya fue planteada en Paz y Meliá, A.: op. cit., 15 (5 de agosto de 1876), p. 259. Si se tiene en cuenta el constante afán de Milán en su libro por demostrar su superioridad sobre Fernández, podría incluso pensarse en la posibilidad de que las nuevas poesías de respuesta con que, según el duque, "se ha mejorado Joan Fernández" fuesen obra del propio autor del libro y no de Fernández. 


\section{HACIA UNA REVISIÓN DE LA IDENTIFICACIÓN DEL MÚSICO Y ESCRITOR CON LLUÍS DEL MILÀ I EIXARCH}

Con frecuencia se ha identificado, con mayor o menor cautela, al vihuelista y escritor Luis Milán con el noble valenciano Lluís del Milà i Eixarch. Del primer personaje no se dispone de datos relevantes para su biografía constatados documentalmente, aparte de su condición nobiliaria que se desprende directamente de sus obras, mientras que del segundo contamos en la actualidad con un volumen apreciable de información sobre su trayectoria vital. A pesar de ello, no existe evidencia documental alguna que otorgue a tal identificación ni siquiera indicios de veracidad. Por esta razón, es todavía hoy una cuestión crucial el conocer más sobre las posibilidades de esta identificación, para lo cual va a ser de gran utilidad el ms. 2050 de la Biblioteca de Catalunya.

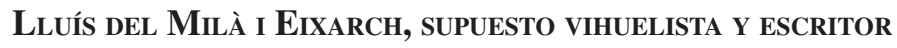

Lluís del Milà i Exarch fue uno de los, al menos, tres hijos varones (Pere, Joan y el propio Lluís) de Lluís del Milà i Llançol, señor de Massalavés y pariente de los poderosos Borja, y de Violant Eixarch. Es importante señalar, en vistas a la interpretación de los nuevos datos que aporta el Proceso de coplas de burlas, que Lluís del Milà i Llançol padecía una enfermedad mental de tal gravedad que fue necesario el nombramiento de un curador o tutor en 1533 que gestionara sus intereses. Su propio hijo Lluís afirmó, en el transcurso de un pleito, que su padre era demente desde antes de 1524 hasta su muerte en 1548, añadiendo que "moltes persones e cavallers e altres persones burlaven e reyen del dit don Luýs del Milà com de persona dement, tractant e reputant aquell com a persona dement" ${ }^{29}$. Este estado de incapacidad mental, motivó que fuera conocido como "el enfermo"30.

29 Trad.: "muchos señores, y caballeros y otras personas se burlaban, y se reían de dicho don Lluís del Milà como de persona demente, tratando y reputando aquél como persona demente". Otras frases que pronunció su propio hijo Lluís en el mismo pleito con el fin de justificar la incapacidad mental de su padre se incluyen a continuación. "[...] don Luýs anava per les carreres de la ciutat de València parlant $a b$ chichs e ab persones de baxa condició, burlant e rient ab ells, e aquells rehien d'ell com de persona dement." (Trad.: "[...] don Lluís iba por las calles de la ciudad de Valencia hablando con niños y con personas de baja condición, burlando y riendo con ellos, y aquéllos se reían de él como persona demente.”); “[...] don Luýs del Milà anava e acostumava anar a comprar a la carniceria y peixcateria, y lo que comprava ho posava en la capilla o en la falda, y los que staven presents se rehien y burlaven d'ell com de persona dement." (Trad.: “[...] don Lluís iba y acostumbraba a ir a comprar a la carnicería y pescadería, y lo que compraba lo ponía en la capilla o en la falda, y los que estaban presentes se reían y burlaban de él como de persona demente.”); "[...] don Luýs del Milà, en lo temps que era viva sa muller, deya que·s volia casar ab moltes, axí com les veya, y les anava pregant que·s casassen ab ell.” (Trad.: “[...] don Lluís del Milà, en el tiempo en que vivía su mujer, decía que se quería casar con muchas, en cuanto las veía, y les iba rogando que se casaran con él.”) [E-VAar, Procesos de Madrid, P, 62, ff. 69r-70v].

30 Así le llama su propio nieto Josep Alfons del Milà en una carta datada en 1578 ó 1579, unos treinta años tras la muerte de su abuelo. Dormer, Diego José (ed.): Progressos de la Historia en el reino de Aragón, y elogios de Gerónimo Zurita, su primer coronista. Zaragoza, Herederos de Diego Dormer, 1680, p. 511. Este apodo fue recogido por primera vez en tiempos modernos, según nuestro conocimiento, en SAN Petrillo, Barón de: Los Cruílles y sus alianzas. Valencia, Imprenta Diana, 1946, p. 189. 


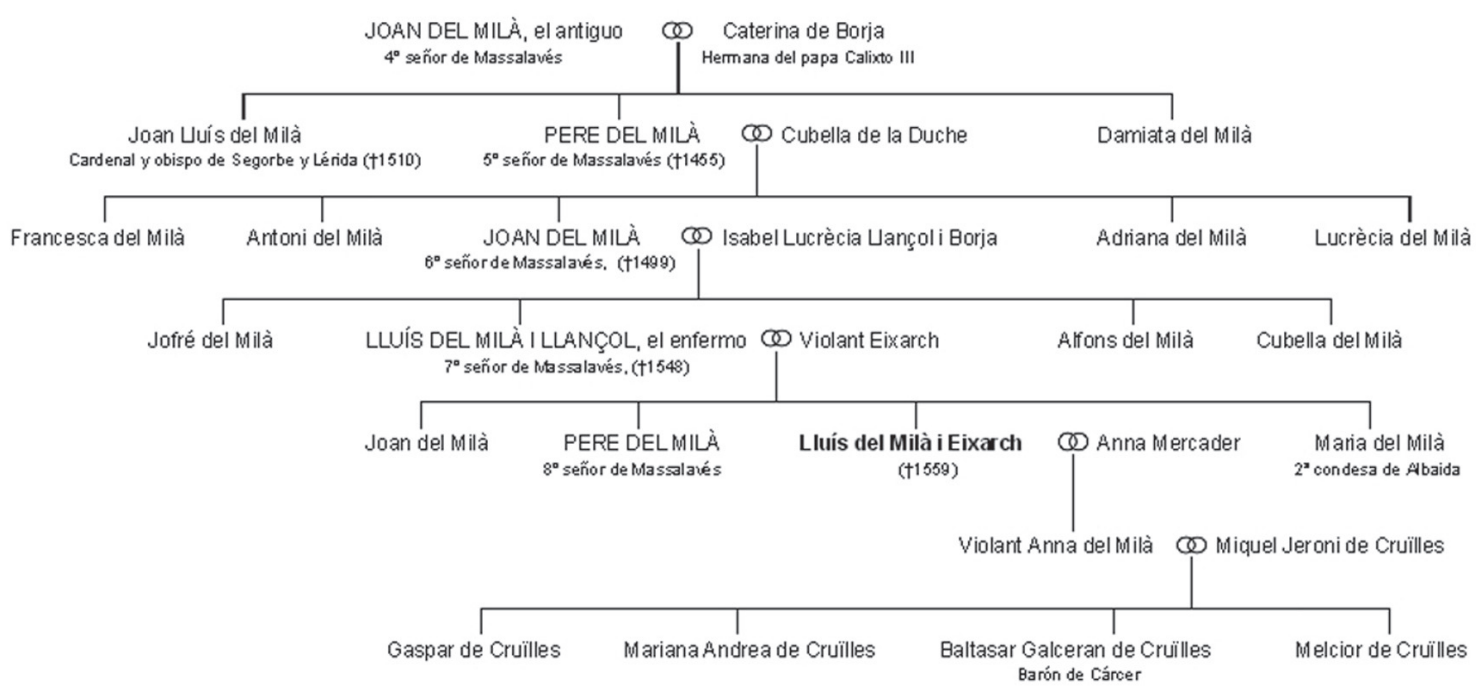

Figura 1. Ascendientes por línea paterna y descendientes de Lluís del Milà i Eixarch ${ }^{31}$

Vicent Josep Escartí ha realizado la mayor aportación de datos sobre la biografía de Lluís del Milà i Eixarch, informándonos de que este personaje habría nacido seguramente después de 1506, de su condición de clérigo, de sus frecuentes pleitos por intereses familiares, de su matrimonio con Anna Mercader -con la que tuvo al menos una hija llamada Violant Anna- y de su muerte en 1559 en la ciudad de Alzira, donde se encontraba huyendo de la peste ${ }^{32}$.

\section{UNA BREVE RETROSPECTIVA HISTORIOGRÁFICA SOBRE LA IDENTIFICACIÓN}

La identificación del vihuelista y compositor Luis Milán con Lluís del Milà i Eixarch surge y toma fuerza progresivamente en obras de autores pertenecientes a la nobleza valenciana de finales del siglo XIX y primera mitad del siglo xx. En 1891 está datado un manuscrito, recientemente llevado a la imprenta, de Vicente Salvador y Montserrat, cuarto marqués de Cruïlles, titulado Noticias y documentos relativos a doña Germana de Foix, última reina de Aragón. En esta obra, el marqués

31 Fuentes: San Petrillo, Barón de: op. cit., pp. 188-190; Batllori, Miquel: La família Borja, Obra completa, vol. IV. Valencia, Tres i Quatre, 1994; MiLÀ, Lluís del: El Cortesano, ed. de Vicent Josep Escartí, vol. 1, op. cit., pp. 39-53; E-Mh, D-46, ff. 20r-20v.

32 Estos datos fundamentales, junto con otros detalles biográficos que aquí no se citan pueden encontrarse, con su justificación documental, en MiLÀ, Lluís del: El Cortesano, ed. de Vicent Josep Escartí, vol. 1, op. cit., pp. 39-53. 
considera al autor de El Cortesano "entre los ascendientes de nuestra familia" ${ }^{33}$. Se ha de observar en este punto que Violant Anna del Milà, la hija de Lluís del Milà i Eixarch, emparentó con los Cruïlles por su casamiento con Miquel Jeroni de Cruïlles (ver figura 1). Ocho generaciones después, puede localizarse, sin lugar a dudas, a Vicente Salvador y Montserrat como descendiente directo de Lluís del Milà i Eixarch, a quien el marqués consideraba el músico y escritor ${ }^{34}$. Pocos años más tarde, en 1903, José Ruiz de Lihory, barón de Alcahalí, planteaba explícitamente la posibilidad de esta identificación, aunque sólo de manera hipotética, aportando un documento en que se citaban a diversos miembros de la familia de Lluís del Milà i Eixarch ${ }^{35}$. El paso definitivo, por el que consideró explícitamente la identificación como un hecho cierto, a pesar de no haber aparecido nuevas pruebas ni documentos, se produjo no más tarde de 1946, año en que el barón de San Petrillo afirmó tajantemente que Violant Anna del Milà fue hija de "Don Luis Milán, el autor de la conocida obra llamada El Cortesano" ${ }^{36}$.

A partir de este momento y hasta el presente, los biógrafos de Luis Milán habitualmente han optado bien por la aceptación de la veracidad de la identificación, sin plantearse duda alguna, o bien por la mención como simple posibilidad, exponiendo en alguna ocasión las dudas, especialmente derivadas del problema que, de aceptarse la identificación, existiría en relación a la fecha de impresión de El Cortesano. En el colofón de esta obra se explicita que la obra había sido impresa en 1561, tras ser "corregida a voluntad y contentamiento del autor". Dar por buena la identificación conduciría, pues, a aceptar la extraña circunstancia de que la corrección de la impresión debería de haber concluido, al menos, dos años antes de la salida de la imprenta, ya que el hijo del señor de Massalavés, su pretendido autor, había fallecido ya en $1559^{37}$. Curiosamente, la postura de la aceptación incondicional ha sido la predominante en las publicaciones del mundo de la filología, mientras que la cautela ha prevalecido en el campo musicológico.

Entre los que han asumido la identificación, asignando al vihuelista datos de Lluís del Milà i Eixarch, encontramos a Josep Romeu $(1951)^{38}$, Samuel Rubio $(1983)^{39}$, Teresa Ferrer (1993) ${ }^{40}$, Josep Solervicens

$33 \boldsymbol{E}$-VA $b v$, Ms/95. La edición moderna contiene la cita en: CruïlLEs, Marqués de: Noticias y documentos..., op. cit., p. 406 , nota 25 .

34 La biografías de los descendientes directos de Violant Anna del Milà que dieron origen al marquesado de Cruïlles son minuciosamente estudiadas en SAN PETRILLO, Barón de: op. cit., pp. 188-259. Los árboles genealógicos esquemáticos en pp. 154, 232.

35 “[...] en manera alguna respondemos de la exactitud en la conexión”. RuIz DE LiHORY, José: La música en Valencia. Diccionario biográfico y crítico. Valencia, Establecimiento Tipográfico Doménech, 1903, pp. 333-334. La posibilidad apuntada por Ruiz de Lihory fue recogida por el musicólogo J. B. Trend en 1925 [Trend, John Brande: Luis Milan and the vihuelistas. Humphrey Milford, Oxford University Press, 1925, pp. 12-13].

36 San Petrillo, Barón de: op. cit., p. 188.

37 Escartí no pasó por alto este problema y propuso algunas posibles soluciones, como un hipotético retraso de la impresión debido a la peste que afectaba a la ciudad [Milà, Lluís del: El Cortesano, ed. de Vicent Josep Escartí, vol. 1, op. cit., pp. 52-53].

38 Romeu i Figueras, Josep: "Literatura valenciana en "El Cortesano" de Luis Milán”, Revista Valenciana de Filología, 1 (1951), p. 413.

39 Rubio, Samuel: "Desde el "ars nova" hasta 1600" en Historia de la Música Española, vol. 2. Madrid, Alianza Editorial, 1983, p. 221.

40 Ferrer Valls, Teresa: Nobleza y Espectáculo Teatral (1535-1622). Valencia, UNED, Universidad de Sevilla, Universitat de Valencia, 1993, p. 112, nota 3. 
$(1997)^{41}$, Vicent Josep Escartí $(2001,2009,2010)^{42}$, Isabel Vega (2006) ${ }^{43}$, María Lorenzo (2009) ${ }^{44}$ o Rosa Elena Ríos Lloret (2009) ${ }^{45}$. Entre todos estos trabajos ha representado un hito el de Escartí de 2001, por ser el primero que, desde la obra de Ruiz de Lihory, ha aportado información novedosa, y además en apreciable volumen, sobre el hijo del señor de Massalavés, a pesar de que los documentos presentados de ningún modo prueban su conexión con el vihuelista.

En el grupo de los autores más cautelosos en relación a la identificación se han alineado Luis Gásser $(1996)^{46}$, John Griffiths $(2002,2009)^{47}$ y Gerardo Arriaga $(2007,2008)^{48}$. Entre ellos merece una mención especial el primero de los trabajos citados de Arriaga, donde expone con gran claridad y detalle el estado de la cuestión biográfica del músico, formulando razonadamente sus reservas a la identificación.

\section{Aportaciones del Proceso de coplas de burlas del ms. 2050 de la Biblioteca de Catalunya}

Todavía en el siglo xIx, Francisco Asenjo Barbieri $(* 1823 ; \dagger 1894)$ observaba que existían dos personas llamadas Luis Milán en la Valencia de la época, según se desprendía de las poesías de la particular batalla poética contenidas en el impreso de las obras de Fernández de Heredia ${ }^{49}$. En efecto, puede identificarse en esta fuente $(B)$, única que Barbieri declaró haber consultado, un pasaje de uno de los poemas de Fernández (correspondiente al $n^{\circ} 22$ de nuestra edición) que claramente pone de manifiesto por duplicado (vv. 9 y 11 teniendo muy en cuenta la nota $\mathrm{n}^{\circ}$ 52), la existencia de dos Luis Milán ${ }^{50}$. No obstante, la fuente $A$, no considerada por Barbieri ni Arriaga, no concuerda ya que se refiere en una ocasión a dos (v. 11), pero en otra a tres personas homónimas (v. 9).

41 Solervicens i Bo, Josep: El diàleg renaixentista, Joan Lluís Vives, Cristòfor Despuig, Lluís del Milà, Antoni Agustí. Barcelona, Publicacions de l'Abadia de Montserrat, 1997, p. 169, nota 171.

42 Milà, Lluís del: El Cortesano, ed. de Vicent Josep Escartí, vol. 1, op. cit., pp. 39-53; Escartí, Vicent Josep: “Aportació a la biografia i a la ideologia de Lluís del Milà”, en Miscel-lània Joaquim Molas, vol. IV. Barcelona, Publicacions de l'Abadia de Montserrat, 2009, pp. 23-53; MiLÀ, Lluís del: El Cortesano, ed. de Vicent Josep Escartí, op. cit., pp. 27-35..

43 Milán, Luis de: El libro de motes de damas y caballeros de Luis de Milán: Edición crítica y estudio, ed. de Isabel Vega Vázquez. Santiago de Compostela, Universidade de Santiago de Compostela, 2006, pp. 9-12.

44 Lorenzo, María: "Milán, Luis de", en Pablo Jauralde Pou (ed.), Diccionario filológico de literatura española del siglo XVI. Madrid, Editorial Castalia, 2009, p. 376. La autora asume la identificación cuando indica que Milán falleció en Alzira en 1559.

45 Ríos Lloret, Rosa Elena: “Amor, deseo y matrimonio en El Cortesano de Lluís del Milà”, Tiempos Modernos, 18 (2009), p. 1. < http://www.tiemposmodernos.org/tm3/index.php/tm/article/view/153/204>.

46 GÁsser, Luis: Luis Milán on sixteenth-century performance practice. Bloomington and Indianapolis, Indiana University Press, 1996, p. 4.

47 Griffiths, John: “Milán, Luis”, en Emilio Casares Rodicio (ed.), Diccionario de la Música Española e Hispanoamericana, vol. 7. [Madrid], Sociedad General de Autores y Editores, 2002, p. 564; ID.: "Milán, Luys [Luis]", en Grove Music Online, http://www.oxfordmusiconline.com [Consulta: junio de 2010]; ID.: "Hidalgo, mercader, sacerdote o poeta: vihuelas y vihuelistas en la vida urbana", Hyspanica Lyra, 9 (2009), pp. 18-19..

48 ArRiaga, Gerardo: "Reflexiones en torno a Luis Milán: vida, obra, historiografía", Roseta, 0 (2007), pp. 6-34; MiLÁN, Luis: Libro de música de vihuela de mano intitulado 'El maestro', ed. facsímil de Francisco Roa, estudio de Gerardo Arriaga. Madrid, Sociedad de la Vihuela, 2008, pp. IX-XIV.

49 "Parece que además del conocido maestro de vihuela poeta autor del Cortesano, había otro en su tiempo del mismo nombre y apellido. Para aclarar este asunto, hay que ver despacio las obras de D. Juan Fernández de Heredia, Valencia, 15... en 8. . (Biblioteca Nacional 324-8) desde el folio 150 al 170, donde se hallan también noticias curiosas para la biografía de D. Luis Milán." [Tomado de la edición BARBIERI, Francisco Asenjo: Biografías y documentos sobre Música y Músicos Españoles (Legado Barbieri), ed. de Emilio Casares, vol. 1. Madrid, Fundación Banco Exterior, 1986, p. 331]. También Paz y Meliá, con alguna reserva, apuntó en 1876 en la misma dirección que Barbieri [PAZ y Meliá, A.: op. cit., 15 (5 de agosto de 1876), p. 258].

50 Gerardo Arriaga identificó el poema en cuestión [ARriaga, Gerardo: "Reflexiones...”, op. cit., pp. 13-14; Milán, Luis: Libro de música de vihuela de mano..., op. cit., p. xiv]. 
Poema n ${ }^{\circ} 22$, vv.1-13 (A, f. 136r $)^{51}$

1 Señor don Luis Ferrer, quien las coplas me a traýdo, como apenas l'e [e]ntendido. no puedo bien responder.

5 Pregunté: ¿por quién se dan las coplas no me dirés? Dixo: en ellas lo verés; por don Luis del Milán. Como hay tres ${ }^{52}$ no sé quál es.

10 El re, mi, fa, sol declara quál es de los dos señores, con puntos que son mayores ${ }^{53}$ que si fuesen por la cara. ${ }^{54}$

Sobre esta confusa cuestión, la rúbrica de $A$ al poema $n^{\circ} 16$ aporta una valiosa información que no transmiten el resto de fuentes, y que hasta ahora no ha sido considerada, que apunta a la existencia de tres personas, y no dos, entre las que se establecen relaciones concretas de parentesco:

Respuesta de don Joan Fernández, en la qual nota a don Luis de los malos consonantes, y responde al apodo; y juntamente dize que aquellas coplas, su tío don Luis Milán, el loco, se las debe ayudar a hazer; y por que se entienda de qual don Luis habla, porque ay otro primo suyo, declárase..$^{55}$

Por tanto, el vihuelista y poeta tenía un tío -apodado "el loco"- y un primo llamados también Luis Milán. Como ya se ha expuesto, la demencia acompañó a Lluís del Milá i Llançol desde 1524, según el testimonio ya citado de su propio hijo Lluís del Milà i Eixarch, por lo que parece claro que éstos eran el padre e hijo que aparecen en el poema $\mathrm{n}^{\mathrm{o}} 16$ (vv. 43-44), y al mismo tiempo tío y primo, respectivamente, del músico y escritor. De este modo, también se explica quiénes son la "trinidad" (v. 45) o las "tres personas" (v. 46) a las que se refiere el mismo poema: los tres Luis Milán.

51 Puesto que este poema se encuentra en $A, B$ y $C$, se reproducen aquí los fragmentos poéticos de mi edición, basada en $A$, aunque se incluyen sus variantes más significativas a pie de página. Análoga consideración es aplicable a los fragmentos de los poemas que se reproducen más abajo.

$52 B, C$ : "dos". Se recuerda que la fuente básica que se reproduce es $A$.

$53 B, C$ : "peores".

$54 A$, f. $136 \mathrm{r}$

55 A, f. 129 r. 
Poema n 16 , vv. 41-48 (A, f. 130r):

41 Otro don Luis, señor,

dizen qu'es con vos, sin duda;

si es el padre el que os ayuda,

el hijo fuera mejor.

45 Esta trinidad juntada,

si con tres personas lucho,

aunqu'el uno ${ }^{56}$ tengo en mucho,

los otros no tengo en nada.

En la rúbrica del poema $\mathrm{n}^{\circ} 18$ de la misma fuente se vuelve a recalcar la existencia de tres personajes, y no dos, aunque en esta ocasión se habla de un tío y un sobrino -y no un primo- del autor. No obstante, todo apunta a que el término "sobrino" en este caso es una errata por "primo", puesto que así aparece en la rúbrica de la "respuesta pasada" -es decir, el poema no 16 - a la que alude la propia rúbrica del poema n 18 :

Respuesta de don Joan Fernández a don Luis del Milán, en la qual torna a tocar lo que dixo en la otra respuesta pasada, y es que su tío o sobrino le ayudan a hazer las coplas; y agora dize que no, sino que le dan de comer, y tócale del yr mal vestido y senzillo en invierno. ${ }^{57}$

En efecto, una lectura cuidadosa del poema n ${ }^{\circ} 18$ confirma la existencia de tres personas -el "mozo" o el "padre" (dependiendo de fuentes), el "otro", y "vos" (el vihuelista)-, siendo el músico el sobrino de uno de los otros dos ${ }^{58}$.

Poema nº 18, vv. 13-19 (A, f. 133r):

De los don Luyses dos, el moço en otro socorre ${ }^{59}$,

15 mas en coplas ya se corre si le dizen qu'es con vos.

Antes de vuestro trobar, está diziendo con tino: más os valiera, sobrino, 20 de las coplas no curar.

56 B, C: "hijo".

57 A, f. $132 \mathrm{v}$.

58 Los últimos poemas mencionados $\left(\mathrm{n}^{\circ} 16 \mathrm{y} \mathrm{n}^{\circ} 18\right)$ estaban ya presentes en la fuente B difundida a través de las dos ediciones modernas, aunque difícilmente se podían comprender los fragmentos reproducidos sin la ayuda de las rúbricas de $\mathrm{A}$, puesto que ni siquiera se citan en ellos los apellidos ("Milán") de los otros "don Luyses dos".

$59 B, C$ (verso 14): "el padre en otro os socorre". 


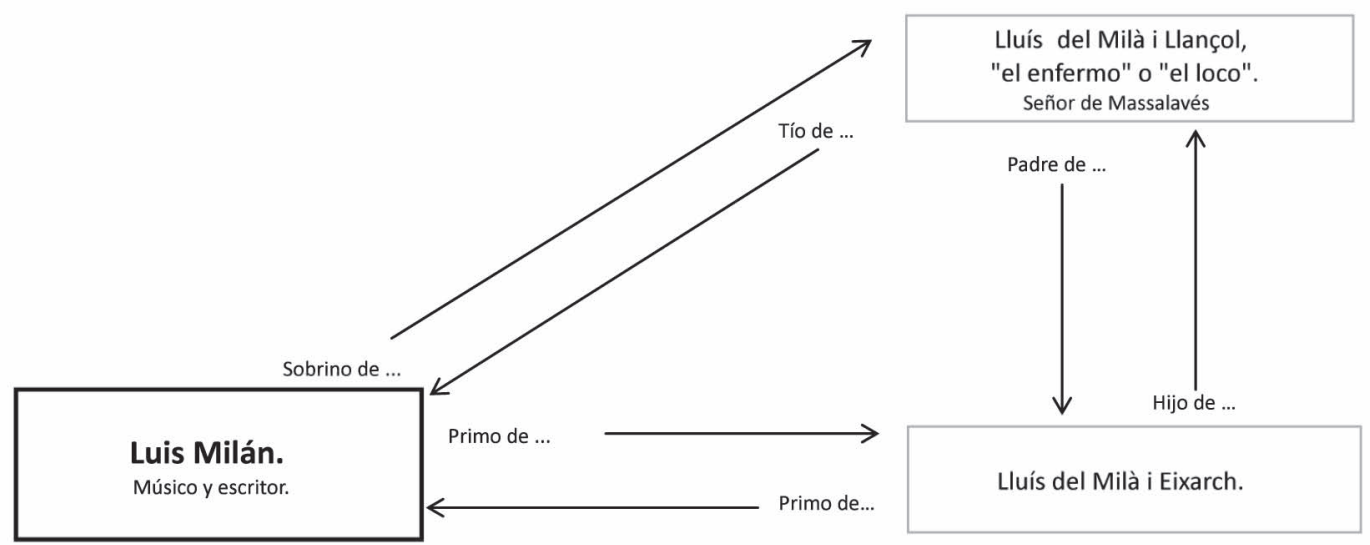

Figura 2. Relaciones de parentesco entre los tres Luis Milán

La aceptación de la existencia de estos tres personajes homónimos y sus relaciones de parentesco dan luz sobre un par de circunstancias conocidas que no tenían una explicación satisfactoria. En primer lugar, como primo de Lluís del Milà i Eixarch, el músico también guardaba este parentesco con Pere del Milà i Eixarch, hermano del primero, quien debió de ser el "Pedro Milán" que aparece en $E l$ Cortesano y a quien Germana de Foix llama "vuestro primo" dirigiéndose al autor de la obra ${ }^{60}$. De otro lado, desaparece el problema que se planteaba en relación con el colofón de El Cortesano, ya que con la separación de identidades del vihuelista y Lluís del Milà i Eixarch no existe ningún inconveniente para pensar que el primero todavía estuviera vivo en 1561 para poder realizar las correcciones poco antes de la impresión, tal como se había mantenido por todos los biógrafos hasta el trabajo de Escartí de 2001.

Únicamente quedaría pendiente de una explicación la referencia del poema $n^{\circ} 22$ en las fuentes $B$ y $C$ a sólo dos Luis Milán (vv. 9 y 11). En el caso de la fuente $A$ se habla de dos (v. 11) pero también de tres (v. 9), como ya se ha mencionado. Una posible explicación para esta aparente incoherencia es que en esa ocasión no se tuviera en cuenta al tío del autor ya que, por su incapacidad mental, no parece probable que fuera un asistente a aquellas veladas cortesanas. En todo caso, la probabilidad de que realmente fueran dos los Luis Milán, que se apoyaría únicamente en este poema (e incluso no claramente en las tres fuentes), parece mínima frente a la coherencia de toda la argumentación anteriormente expuesta que, basándose en un mayor volumen de detallados textos, apoya la existencia de los tres homónimos.

60 “Dixo la reyna: -Don Luys Milán: por vida de don Pedro Milán, vuestro primo, que leáys, que yo’s prometo de oyr de buena gana, por ser la obra milana.” [MiLÀ, Lluís del: El Cortesano, ed. de Vicent Josep Escartí, vol. 1, op. cit., p. 390]. Arriaga ya había puesto la atención en la existencia de este pasaje [ARRIAGA, Gerardo: "Reflexiones...", op. cit., p. 14]. 
Otra aportación biográfica de la fuente $A$, en este caso en la rúbrica del poema $\mathrm{n}^{\circ} 14$, es la consideración de la paternidad del vihuelista no sólo cómo una posibilidad, como se desprende del texto del poema y como hasta ahora se había considerado, sino como un hecho cierto.

Respuesta de don Joan Fernández a don Luis del Milán, en la qual se toca cómo lo avían hechado de casa del obispo de Sogorbe, y de un consonante falso que pone en las coplas y, al fin, de un hijo suyo que llevava como paje detrás ${ }^{61}$.

\section{CONCLUSIONES}

El ms. 2050 de la Biblioteca de Catalunya nos ofrece en el Proceso de coplas de burlas la versión más completa, ordenada y próxima al contexto creativo de la particular disputa poética que protagonizaron Juan Fernández de Heredia y Luis Milán, incluyendo composiciones inéditas de ambos, así como información en sus rúbricas de gran interés para la mejor comprensión de las composiciones. Asimismo, el Proceso nos permite la inmersión en el ambiente nobiliario y creativo de la Valencia del segundo cuarto de siglo Xvi siendo, en este sentido, un complemento de El Cortesano.

Entre la novedosa información de tipo biográfico que esta fuente nos brinda, destaca sobremanera la contenida en las rúbricas de los poemas $\mathrm{n}^{\circ} 16$ y n ${ }^{\circ} 18$ de las cuales claramente se deduce que, al menos, existieron tres Luis Milán en la Valencia de la época, siendo el músico y escritor sobrino de Lluís del Milà i Llançol y primo de Lluís del Milà i Eixarch, hijo del anterior. Este hecho aclara el sentido de los textos de dichos poemas, así como otras circunstancias relacionadas con El Cortesano, conduciendo directamente a la necesidad de plantearse la revisión de la identificación del vihuelista y escritor con Lluís del Milà i Eixarch, su primo, la cual había sido ampliamente asumida en las últimas décadas.

Lamentablemente, esta circunstancia también nos deja a la biografía del autor de El Maestro y El Cortesano prácticamente vacía de contenido y a su vida llena de misterio. A pesar de ello, la nueva pista de su vinculación familiar puede ser un firme punto de partida para investigaciones futuras.

$61 A$, f. $127 \mathrm{v}$. 


\section{APÉNDICE}

PROÇESO DE COPLAS DE BURLAS QUE PASARON ENTRE

DON LUIS DEL MILÁN, EL MÚSICO, Y DON JOAN FERNÁNDEZ

FUENTES

- A: Biblioteca de Catalunya, Ms. 2050, ff. 119r-146v.

- B: Las obras de don Joan Fernández de Heredia, assí temporales, como espirituales (Valencia: Joan Mey, 1562), ff. 149r-169v. Se ha consultado el ejemplar de la Biblioteca Històrica de la Universitat de València, sign. BH Z-03 223, disponible a través de internet: http://trobes.uv.es/tmp/ webpac2 1377702.10611 [Consulta: septiembre de 2010].

- $\quad C$ : Biblioteca Nacional de España, Ms. 2621, ff. 154v-169v.

- D: El Cortesano de Luis Milán (Valencia: Joan d'Arcos, 1561). Se ha acudido directamente al facsímil MıL̀̀, Lluís del: El Cortesano, ed. de Josep Vicent Escartí, vol. II. Valencia, Biblioteca Valenciana, 2001.

Los poemas de la fuente base $A$ se han numerado según el orden en que aparecen. Bajo el número de cada poema se indica su localización en las fuentes donde está presente y, a continuación, la rúbrica de $A$.

NOTAS A PIE DE PÁGINA

Se incluyen a pie de página las rúbricas de los poemas presentes en $B$ y $C$, cuando existen, ya que ofrecen bastantes diferencias; en el caso de la fuente $D$, se transcribe el texto previo al poema si añade algún detalle sobre su contexto creativo. Asimismo, se han anotado las variantes textuales que ofrecen las fuentes $B, C$ y $D$ sólo cuando pudieran afectar al significado del texto. El resto de notas incluyen explicaciones de cuestiones relacionadas con el contexto o versan sobre el significado de vocablos que no aparecen en el Diccionario de la Lengua Española de la Real Academia Española (22. ${ }^{a}$ edición, 2001).

CRITERIOS DE TRANSCRIPCIÓN

a) Corrección de erratas manifiestas, indicando en nota a pie de página la forma original.

b) Modernización de la puntuación, acentuación y uso de minúsculas/ mayúsculas.

c) Desarrollo de las abreviaturas.

d) Introducción de partículas omitidas, que se indican entre corchetes. 
e) Separación de las aglutinaciones según el uso actual mediante un apóstrofe. En aras de una mayor claridad, en unos pocos casos, se han separado sin apóstrofe y han añadido las vocales que faltan indicándolas entre corchetes.

f) Se agrupan las palabras que actualmente constan de un único grafema y que aparecen separadas en el texto.

g) Las grafías $u / v$ e $i / j$ se transcriben según sea su valor vocálico $(u, i)$ o consonántico $(v, j)$. Se ha añadido cedilla a la $c$ cuando, sin llevarla en el original, ha sido necesario fonéticamente (ej.: "començando" en lugar de "comencando").

h) Cuando se ha considerado necesario para la correcta comprensión de ciertas formas ortográficas antiguas, se indica en nota a pie de página la forma actual (ej.: "dina" = digna) y se mantiene en el cuerpo principal la forma original.

i) Las inserciones interlineadas del original se señalan entre $<>$.

j) Se indica entre corchetes la foliación.

EDICIÓN ${ }^{62}$

[119r] Aquí se contiene un proçeso de coplas de burlas que pasaron entre don Luis del Milán, el músico, y don Joan Fernández, en el qual se a de notar dos cosas. Y son que como don Joan Fernández. era estremado en todas sus cosas, entre las otras lo era en el vestir, y don Luis del Milán siempre le pega en los vestidos y don Joan a él en sus neceçidades y en el yr mal vestido y, siendo buen músico y mal trobador, siempre hazía lo que menos se le entendía. Y más se a de notar qu'en el discurso d'este proceso se tocan muchas cosas que son al estilo y modo de hablar y tratar valenciano, por lo qual se requiere entendello para que se goze, en espeçial los que son mal pláticos en las cosas de Valençia. Y para que se advier $<$ ta> se señala en la margen con este señal : .

\section{[1]}

[A, ff. 120r-120v / B, ff. 163v-164r (fusionado tras el poema $\mathrm{n}^{\circ} 29$ )].

[120r] Don Luis del Milán hizo este diálogo que toca çierto misterio, y son interlocutores él y don Joan Fernández; y diolo a un cavallero llamado don Ramón Pujadas ${ }^{63}$ para que se lo llevase.

62 Agradezco al filólogo Joaquim Martí Mestre, profesor de la Universitat de València, su gentil ayuda en la resolución de algunas dudas de transcripción.

63 Guillem Ramon Pujades i Mascó fue señor de las baronías de Piles, Finestrat y Rafel [Salazar y Castro, Luis: Árboles de costados de las primeras casas de estos reynos, cuyos dueños vivían en el año de 1683. Madrid, Imprenta de D. Antonio Cruzado, 1795, p. 180]. Este personaje también aparece en $D$, f. b5r. 


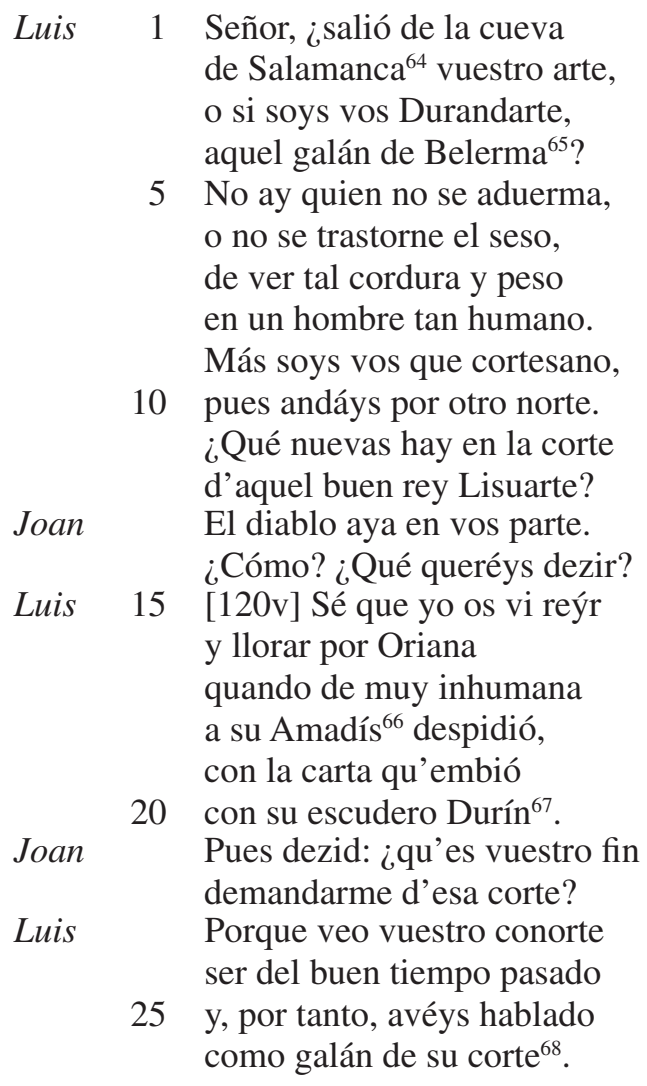

64 La cueva de Salamanca era la cripta de la iglesia de San Cebrián, actualmente inexistente, donde la leyenda cuenta que impartía clases el diablo.

65 Durandarte y su amada Belerma son los protagonistas de algunos romances viejos castellanos de inspiración carolingia. 66 Amadís de Gaula, su amada Oriana y el rey Lisuarte de la Gran Bretaña, padre de ésta, son los personajes principales de una popular serie de novelas de caballería en castellano del siglo XVI.

67 A: "Turín". Durín era el servidor de Oriana que actúo como su correo en su relación con Amadís. d'ella."

$68 B$ (versos 23-26): "Porque veo vuestro corte / de galán muy avisado, / y por tanto haver hablado / d'ella, creo que soys 
[2]

[A, ff. 120v-121v / B, ff. 158v-160r].

Respuesta de don Joan Fernández al diálogo de don Luis del Milán. Y responde también en diálogo, en el qual son interlocutores Pujades, porqu'él traxo el de don Luis, y el mesmo don Joan, y el tesorero, y don Francisco Fenollet ${ }^{69}$, y el comendador Romani ${ }^{70}$, porque todos se hallaron en ello ${ }^{71}$.

Pujades $1 \quad \begin{aligned} & {[121 \mathrm{r}] \text { Como esto toque a mí }} \\ & \text { de parte de un cavallero, } \\ & \text { don Francisco, tesorero, }\end{aligned}$
Joan Fernández, Romaní,
que respondáys os requiero.
$\quad \begin{aligned} & \text { D'este cavallero noble } \\ & \text { yo soy su procurador. }\end{aligned}$

$\begin{aligned} & \text { Él es un gran tañedor } \\ & \text { quitado }\end{aligned}$
$10 \quad$ tiene muy poco primor.

\begin{tabular}{|c|c|}
\hline & $\begin{array}{l}\text { A muchos }{ }^{74} \text { que no pensáys } \\
\text { da liçiones de maestro. } \\
\text { Biscanta }^{75} \text {, mas no muy diestro. }\end{array}$ \\
\hline Joan & $\begin{array}{l}\text { Pues que tanto le alabáys }{ }^{76} \text {, } \\
\text { quitalde y séase vuestro. } \\
{ }^{77} \text { Él inprime una dotrina } \\
\text { harto vieja en el tañer } \\
\text { ciertas reglas de meter }{ }^{78} \text {. }\end{array}$ \\
\hline $\begin{array}{r}\text { Tesorero } \\
20\end{array}$ & $\begin{array}{l}\text { Del tañer haze gallina. } \\
\text { ¡Por Dios, qu'es cosa de ver! }\end{array}$ \\
\hline
\end{tabular}

69 Francesc Gilabert de Fenollet $(* 1489$ c; $† 1548)$ fue sobrino del conde de Oliva Serafí de Centelles. Desempeñó gran parte de su vida el cargo de batlle de Xàtiva. También aparece en diversas ocasiones en $D$. Se conservan poemas suyos en el Cancionero General (Valencia: Hernando del Castillo, 1511) [PEREA Rodríguez, Óscar: Estudio biográfico sobre los poetas del Cancionero General. Madrid: Csic, 2007, pp. 215-226].

70 Posiblemente se trate del caballero Francesc Llançol de Romaní (†1544), quien ocupó diversos cargos en la orden militar de Montesa: comendador de Perputxent, clavero (1523), comendador mayor (1535) y Maestre (1537) [SiETE IgLESIAS, Marqués de: "Caballeros y religiosos de la orden de Montesa (1319-1700)", Hidalguía, 25 (11-12/1957), p. 836].

$71 B$ (rúbrica): "Don Luys Milán embió un colloquio muy largo a don Joan Fernández. Respóndele con otro. Pujadas. Don Francisco Thesorero. Don Joan Fernández. Romani.”. El coloquio citado del vihuelista es el poema ${ }^{\circ} 1$, que en $B$ se encuentra fusionado tras el $n^{\circ} 29$ salvo.

72 La expresión "quitado" seguramente es una traducción literal de la preposición valenciana/catalana llevat = excepto,

73 Debe entenderse este vocablo con la acepción relativa a la música instrumental del siglo XVI, la cual define un tipo de ornamentación. Según Tomás de Santamaría "[...] redoble quiere dezir, puntos doblados, o reyterados, los quales solamente se doblan o reyteran con dos puntos immediatos, assí como mi, re, mi, fa, mi, fa, mi, fa, mi” [SANTAMARía, Tomás de: Libro llamado arte de tañer fantasía. Valladolid, Francisco Fernández de Córdova, 1565, f. 46v; se ha consultado la edición facsímil ed. de Luis Antonio González Marín. Barcelona, CSIC, 2007].

74 B: "muchas".

75 B: "Es cantor".

76 B: "quitáys".

77 B: los versos 16-18 son dichos por Pujades.

78 B: "poner". Probable alusión al impreso El Maestro de Luis Milán. Valencia, Francisco Díaz Romano, 1536. Si así fuese, el tiempo verbal de presente de la poesía podría indicar que ésta se compuso durante el proceso de impresión del libro, es decir, en 1536 o poco antes. 


\begin{tabular}{|c|c|}
\hline Romaní & $\begin{array}{l}\text { Si se le descose suela, } \\
\text { de las calças a lo menos, } \\
\text { ya no preciara menos } \\
\text { los puntos de su vihuela } \\
\text { si para coser son buenos. }\end{array}$ \\
\hline Fenollet & $\begin{array}{l}\text { ¿Aquesta larga escritura } \\
\text { fuiste vos quien la hordenó? }\end{array}$ \\
\hline Pujades & $\begin{array}{l}\text { Digo, señores, que no, } \\
\text { que harta mala ventura } \\
\text { fuera mía hazella yo. }\end{array}$ \\
\hline Fenollet ${ }^{79}$ & $\begin{array}{l}{[121 \mathrm{v}] \text { Dexaos de disimular, }} \\
\text { no's corráys, bolved de tranco. } \\
\text { Aunque venís ruvio y blanco, } \\
\text { por que le hagáys trobar } \\
\text { os dexamos pasar franco. }\end{array}$ \\
\hline Tesorero $^{80}$ & $\begin{array}{l}\quad \text { En començando a leer } \\
\text { diximos al escrivano: } \\
\text { Pues trobáys para en verano, } \\
\text { ¿cómo pudistes traer } \\
\text { cosa tan fría en la mano? }\end{array}$ \\
\hline Pujades & $\begin{array}{l}\text { Moriré si nunca fue } \\
\text { cosa jamás tan reýda, }\end{array}$ \\
\hline Joan $^{81}$ & $\begin{array}{l}\text { Y ansí él, por su caýda, } \\
\text { ha votado de yr a pie } \\
\text { descalço toda su vida. }\end{array}$ \\
\hline Fenollet ${ }^{82}$ & $\begin{array}{l}\text { En las barbas me a tocado, } \\
\text { que va lo blanco teñido. } \\
\text { Si se me huvieran caýdo, } \\
\text { él me dixera pelado } \\
\text { por bien que fuera vestido. }\end{array}$ \\
\hline 55 & $\begin{array}{l}\text { Gran enpresa ha sido, en fin, } \\
\text { meteros vos en tal trance. } \\
\text { Por que más primor alcançe, } \\
\text { dezís que trobe'n latín } \\
\text { quien mal acierta en romançe. }\end{array}$ \\
\hline Romaní & $\begin{array}{l}\text { Cosa que tanto inportuna } \\
\text { no la nombren al revés. } \\
\text { Coloquio }{ }^{83} \text { con tantos pies, } \\
\text { y sin cabeça ninguna, } \\
\text { colloquio }{ }^{84} \text { le digan qu'es. }\end{array}$ \\
\hline
\end{tabular}

79 B: Fernández de Heredia.

$80 B$ : Fernández de Heredia.

81 B: Tesorero.

$82 B$ : Fernández de Heredia.

83 B: "colloquio".

84 En valenciano/catalán, colló = "testículo". B: "culoquio". 
[3]

[A, ff. 122r / B, ff. 151r-151v / D, f. [BviIIv]].

[122r] Scrive don Luis del Milán a don Joan Fernandes sobre que se avia quitado una ropa de grana y puesta una azul $l^{85}$.

$1 \quad$ Nunca vi mejor empresa ni azuleja más galana. Tan turco soys con la grana como con l'azul turquesa.

5 Azulejo, mi señor, turquesa contracaýda. No tengáys ningún temor, que no caeréys de amor en vuestra vida.

\section{[4]}

[A, ff. 122r-122v / B, ff. 151v-152r / C, ff. 157v-158r].

Respuesta de don Joan Fernández a don Luis, en la qual toca un cavallo que le prestó una vez el conde de Almenara ${ }^{86}$.

1 Esas coplas que hazéys pareçe que las caváys, y d'aý viene que sudáys el vestido que traéys.

5 D'esta ropa azul ruýn quiero, por servir a Dios, [122v] partir la media con vos, aunque no soy san Martín.

85 B (rúbrica): "De don Luys Milán a una ropa azul que don Joan Fernández traýa".

D: "Y el puerco le rompió [a Dídac Lladró] la lança con los colmillos y le hirió el cavallo; y dijo estas palabras: «Mahoma, no me faltes». Joan Fernández se rio diciendo: «A no dezirse vuestro cavallo Mahoma, pensáramos que soys moro». Respondiole don Diego: «Mas antes yo lo soy, después que moro con vuestra amistad. Aunque más lo parescistes vos el tiempo que truxistes la turca de grana, que enojastes en traella a dos veranos de caliente y a tres inviernos de frío; que don Luys Milán se acordó d'éstos en una copla que os hizo haziendoos turquesa quando sacastes una ropa larga de paño azul como la que traen los pregonamuertos de la cofradía de Santiago [...]»." [D, ff. [Bviiir-Bviiiv]].

86 B (rúbrica): "Responde don Joan Fernández".

$C$ (rúbrica): "Don Luys Milán hizo una copla a una ropa azul que don Joan traýa diziendo que era turquesa contracaýda, y él cavalgava con un cavallo hevero del conde de Almenara". Las coplas citadas del vihuelista son el poema n⿳⺈, no incluido en $C$. 
Pues turquesa es menester,

10 no devéys de rehusallo, porqu'en cavalgar cavallo sabéys que avéys de caer.

D' aqueste miedo dezín ${ }^{87}$ : ¿quién su cavallo os prestara,

15 sino el conde d'Almenara ${ }^{88}$ que lo quiere más que a sí? ${ }^{89}$

[5]

[A, ff. 122v-123 / B, ff. 152r-152v (los últimos versos son los 1-4 del nº7)].

Réplica de don Luis del Milán a don Joan Fernández ${ }^{90}$.

1 Don Joan, Turcas maneras, : ¿quién os hizo andador ${ }^{91}$ ?, porque vos no soys dador ni de burlas ni de veras ${ }^{92}$.

5 A tan engañoso fin, Dios por su piedad obre, pues que más soys para'l pobre que no para san Martín ${ }^{93}$.

No lo tengo a maravilla

10 que por tales ${ }^{94}$ os tengáys. Deve ser porque gustáys de san Martín de Castilla.

Es tal la virtud de aquél de su nombre inprimidor, 15 que a quien más le tiene amor, se le pega el nombre d'él.

$87=$ decid

88 Fernando de Próxita (*1503; †1574), quien heredó el condado de Almenara en 1523 , a la muerte de su padre Gaspar de Próxita [Esquerdo, Onofre: Nobiliario Valenciano, vol. I, ed. de José Martínez Ortiz. Valencia, Biblioteca Valenciana, Generalitat Valenciana, 2001, pp. 62-63].

89 La respuesta de Juan Fernández al poema n³ en $D$ es totalmente diferente al que transmiten el resto de fuentes: "Nombrar mi ropa azuleja / de azulejo fue tomado; / paresce que avéys sacado / vestido de ropa vieja." f. Cir].

Turco y turquesa me hezistes; / corristes carrera vana. / Búfalo me parecistes, / que l'azul aborrecistes / por la grana." [D,

90. B (rúbrica): "Don Luys Milán a don Joan".

91 En Valencia se llamaba "andador" a aquella persona que, en las colectividades ciudadanas (cofradías, gremios...) tenía la función de avisar a sus miembros.

$92 B$ (versos 3-4): "como soys tan gran dador / no lo devéis dezir de veras".

93 B (versos 7-8): "porque yo no soy el pobre, / para ser vos sant Martín".

94 B: "Martín". 
[123r] La ropa quiero besar a devoto de tal santo, pero no partáys el manto

20 que no es para cortar.

Dios os cumpla vuestro fin de veros canonizado, y con fiesta çelebrado con tal santo san Martín ${ }^{95}$.

\section{[6]}

[A, ff. 123r / B, ff. 152v-153r / C, ff. 168v-169r].

Respuesta de don Joan Fernández a don Luis, en la qual le toca la inpotencia y poca esperiencia ${ }^{96}$.

1 Dar de san Martín razón, hasta el vino es maravilla, él que nunca entró en Castilla ni aun en tierras de León.

5 Sienpre fuistes de Levante, y aún d'aý dize la gente qu'estáys malsano delante, y muy peor de poniente ${ }^{97}$.

Sépase de aqueste mal ${ }^{98}$

10 que ay diversas opiniones,

: $\quad$ si está el daño en las pensiones o en la suerte principal.

Si está en todo, es más afrenta y daño en tal cavallero,

15 que no le valga un dinero el prinçipal ni la renta.

$95 B$ : continúan los versos que corresponden a los números 1-4 del poema $n^{\circ} 7$ de $A$, lugar éste último que parece su ubicación correcta.

96 B (rúbrica): "Responde don Joan Fernández".

C (rúbrica): "Responde Joan Fernández a las coplas de don Luys, que empieçan: Don Luys Turcas maneras". El poema citado del vihuelista es el $\mathrm{n}^{\circ} 5$, no incluido en $\mathrm{C}$.

$97 B, C$ (versos 6-8): "huystes d'yr a poniente, / y aun d'aý dize la gente, / qu'estáys malsano delante".

98 Se está refiriendo a la sífilis, llamada en la época "mal francés" y a los sarpullidos o llagas que produce. 
[7]

[A, ff. 123v / B, f. 152v (sólo los versos 1-4, situados al final del poema ${ }^{\circ}$ 5)]. [123v] Réplica de don Luis del Milán en la qual quiere tocar a don Joan de neceçitado.

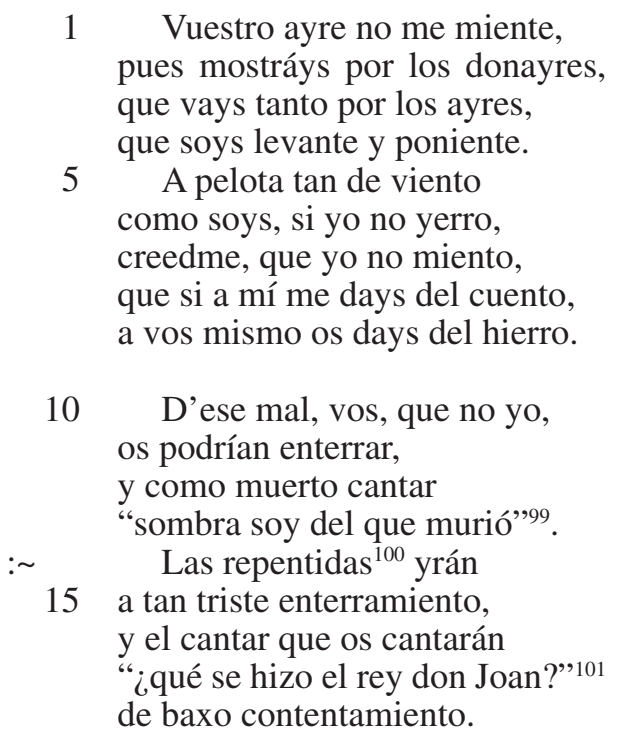

[8]

[A, ff. $123 \mathrm{v}-124 \mathrm{r} / B$, ff.153r-153v (falta verso 9) / C, f. 158v].

Respuesta de don Joan Fernández, en la qual toca un cuento que tres damas le contaron que avían pasado con don Luis hasta que se corrión ${ }^{102}$.

1 [124r] Tres damas estotro día qu'en San Martín estuvieron, burlando sé que os corrieron con aquella copla mía.

$5 Y$ Y de veros tan corrido, temen según os corristes ${ }^{103}$, que tan del todo os perdistes que nunc'avéys pareçido ${ }^{104}$.

\footnotetext{
99 "No soy yo quien ser solía, / no, no, no: / sombra soy del que murió." Villancico [Segunda parte de la Silva de varios Romances. Zaragoza, Esteban García de Nájera, 1550, f. 204].

100 Las arrepentidas (repenedides) eran mujeres que, tras dejar la prostitución, se habían recluido para practicar la penitencia. En Valencia, habitaban en el convento de Sant Gregori.

101 Verso tomado de las Coplas de don Jorge Manrique por la muerte de su padre. 102 B (rúbrica): "Don Joan Fernández a don Luys Milán".

C (rúbrica): "Acertose que tres damas, estando desfreçadas en San Martín, allegó don Luys a ellas y corriéronle con la copla del cavallo del conde de Almenara; y don Joan le haze estas dos sobre cómo se corrió".

103 A: "coristes".

104 = aparecido.
} 
Por esto veros desean,

10 mas vos no las vays a ver, que os bolverán a correr todas las vezes que os vean. Estaos en vuestra posada; si os llaman podréys dezir

15 qu'estáys puesto en escrevir coplas que no valen nada.

\section{[9]}

[A, f. $124 \mathrm{r} / B$, ff. $153 \mathrm{v}-154 \mathrm{r}]$.

Replica don Luis escusándose ${ }^{105}$.

1 Las que no corrido me an no sé cómo lo sentís, an burlado de un Luis, por burlar de un Joan.

5 Pues sabéys que no ay tal, si entráys en la conseja,

: corredor soys de oreja ${ }^{106}$, por mi bien y vuestro mal.

[10]

[A, f. 124v / B, ff. 154r-154v / C, ff. 159r-159v (faltan los versos 17-19)].

[124v] Respuesta de don Joan Fernández, y torna a tocar del cavallo sobre lo mesmo ${ }^{107}$.

1 No negar fuera mejor, que a ley de palacio ussa qu'el corrido que s'escusa, guárdeos Dios de tal dolor.

5 Yo no digo que lo creo, mas las damas y sus dueñas me dan de vos tales señas, que me pareçe que os veo.

105 B (rúbrica): "Respóndele don Luys Milán".

106 Los corredores de oreja (corredors d'orella), constituidos en gremio propio en la ciudad de Valencia, se dedicaban a la intermediación cualificada en negocios de compraventas y de préstamos.

107 B (rúbrica): "Responde don Joan".

$C$ (rúbrica): "Responde a esto don Luys diziendo que no era él, que por otro le tomaron; y en esta respuesta da senya que no podía ser sino él”. La respuesta del vihuelista aludida es el poema n ${ }^{\circ} 9$. 
$Y$ entre las señas que dan

10 por que mejor las creyese, que cantando las oyese este romançe galán:

“ $\mathrm{O}$, don Luis del Milán!, sobre ser viejas las botas,

15 las calças llevava rotas y no el cavallo alazán.

Qu'es overo aunque prestado, y él sólo cavalga en él, por dezir que a cavalgado."

[11]

[A, ff. $124 \mathrm{v}-125 \mathrm{r} / B$, ff. $166 \mathrm{v}-167 \mathrm{r}]$.

Réplica de don Luis del Milán, y açertose en esta sazón que don Joan Fernández hazía vender un su caballo; y tócale d'esto y de que se dava pebrada ${ }^{108}$; y conpárale a un cavallo de metal qu'está en San Martín $^{109}$ de Valencia ${ }^{110}$.

1 [125r] En la cuenta estoy, señor, hast'aquí yo m'e perdido, que si nunca os he corrido,

: $\quad$ es porque soys corredor.

5 Buen oficio avéys tomado, corredor, por no correros bien avéys negociado, si la silla avéys salvado por teneros.

10 El rodado emblanqueçe, corredor es como un gamo, Dios le preste a su amo, pues en todo le pareçe.

Yo tengo muy gran reçelo

15 que no's quede en la posada, y si queda por el pelo, dalde a pelo y a repelo la pebrada.

108 La pebrada era un tinte que se utilizaba para los cabellos [TERRón GonZÁLEZ, Jesús: Léxico de cosméticos y afeites en el Siglo de Oro. Cáceres, Universidad de Extremadura, 1990, p. 117].

109 Se trata del grupo escultórico de bronce que representa a san Martín a caballo partiendo su capa con un pobre (1494), atribuido al flamenco Pieter de Beckere y ubicado sobre la puerta principal de esta parroquia valenciana en la calle de Sant Vicent.

110 B (rúbrica): "Don Luys Milán a don Joan, sobre un cavallo que hirió". 
Si le dexan por no tal,

20 salvalde vos de ruýn, presentalde a san Martín,

: $\quad$ como [e]stá [a]quél de metal.

Y si el santo es burlador y os le bolviere al establo,

25 no será por ser traydor, sino porqu'es mejor para el diablo.

[12]

[A, f. 125v / B, ff. 167r-167v / C, ff. 169r-169v].

[125v] Respuesta de don Joan Fernández a don Luis del Milán, en la qual le tacha que a perdido mucho del tañer ${ }^{111}$.

1 ¿No me diréys, aunque os toca, si es posible que no os duela?

Sacáys como mala muela, malas coplas de la boca.

5 Si son diablos, señor, con conjuros vale más que las saquéys por detrás, por boca del salvonor.

Pues no podéys açertar

10 en trobar ni componer, dançáa ${ }^{112}$, que vuestro tañer es tañer para dançar.

Con todo, es mala fortuna qu'estéys del tañer, sin duda,

15 como mochacho que muda, que no's queda boz ninguna.

Cantar mal y porfiar, cantá ${ }^{113}$, que aunque mal cantéys, cantáys mejor que tañéis.

$111 B$ (rúbrica): "Responde don Joan, y en aquéllas havía compuesto don Luys un motete, y estava distraýdo del tañer.". Entre los versos 16 y 17 se indica "Villancico".

$C$ (rúbrica): "Otras suyas contra don Luys Milán".

112 = danzad.

113 = cantad. 


\section{[13]}

[A, ff. $125 \mathrm{v}-127 \mathrm{v} / B$, ff. $167 \mathrm{v}-168 \mathrm{v}$ (faltan los versos 37-81)].

Réplica de don Luis del Milán, en la qual se a de notar que, siendo el dicho don Luis despedido de comer del palacio [126r] del obispo ${ }^{114}$ de Sogorbe ${ }^{115}$, toca a don Joan porque es muchas vezes combidado del obispo, y va tocando algunos cavalleros amigos de don Joan, en espeçial a miçer Martín Ponçe $e^{116}$, equivocando de los pies porqu'es algo coxo; y al fin, respondiendo a lo del tañer, compárale con un hombre que va por Valencia que se llama Bayla Catalina ${ }^{117} 118$.

1 Engañamundo, señor, de muchos embidiado, mejor soys para engañado, que para desengañador.

5 Vos de vos mesmo sabéys un saber para burlar de muchos que conocéys y de vos, pues componéys ${ }^{119}$ a sabor de paladar

10 Joan, galán y resabido, alabad siempre a Dios, qu'el vestir burla de vos, o vos burláys del vestido.

Vívame tal compañero,

15 de tales trages y modos, que no siendo chocarrero ${ }^{120}$ sabe d'él burlar primero por mejor burlar de todos.

[126v] Bien es esto y no mal, 20 y queréys ver cómo es bien, que sabéys a todos bien en la mesa episcopal.

Obispo me parecéys, pues lo soys en continuar,

25 obispalmente coméys, obispalmente bevéys, Dios os guarde d'enbeudar' ${ }^{121}$.

114 A: "opispo".

115 El obispo de Segorbe en el período 1530-1556 fue Gaspar Jofré de Borja (†1556) [Cárcel OrTí, Vicente: Historia de las tres diócesis valencianas (Valencia: Generalitat Valenciana, 2001), p. 967].

116 Martí Ponç $(† 1554 p)$ fue abogado fiscal del rey en Valencia [Giménez Chornet, Vicent: "Les visites o judicis de residència forals. Un fons documental de l'Arxiu del Regne de València“, en Homenaje a Pilar Faus y Amparo Pérez. Valencia, Generalitat Valenciana, Conselleria de Cultura, Educació i Ciència, 2000, p. 478].

117 Es posible que se trate del personaje llamado "Catalina" que aparece, con voz de tenor, en la ensalada La Negrina. La obra es atribuible, según Maricarmen Gómez Muntané, a Bartolomé Cárceres, músico al servicio del duque de Calabria [FLECHA, Mateo: Las Ensaladas (Praga, 1581), ed. de Maricarmen Gómez Muntané, I. Valencia, Generalitat Valenciana, 2008, pp. 82-84, 162-163].

118 B (rúbrica): "Don Luys Milán a don Joan".

119 B (verso 8): "y de vos pues que sabéys".

120 B (verso 16): "que de gentil cavallero".

121 = embeodar. 
D'enbiudar, quiero dezir, plega [a] Dios no lo seáys,

30 que según lo que papáys, a papa queréys subir.

Si os viese en tal estado, papa por buen papador, yo daría un papado,

35 sólo por veros nombrado papa Joan del salvonor.

Vuestro salvonor en metro, a todos pareçe pulla, si trobáys como en la pulla,

40 diros hemos vade retro.

Don Joan de casi modo, galán de buenas raýzes, no tengáys pullero modo, y a tal pulla dalde adobo,

45 que no hieda a las narizes.

[127r] No uséys de tal estilo, que terné con vos gran pleyto; si no dígalo Beneyto, pues que es vuestro pavilo ${ }^{122}$.

50 Si os hazéys d'espavilar, : $\quad$ al Martín que vos sabéys no's iréys [a] aconsejar con Beneyto en el trobar, pues mejoraréys de pies.

55 Si dexáys espavilaros, ternéys ${ }^{123}$ muy más clara lumbre; hazeldo por que os alumbre vuestro amigo el Conde Claros ${ }^{124}$.

Creedme, señor, creed,

60 por vida de vuestra cara, o por la del Fenollet, que pone pies en pared, hecho vuestro garagara ${ }^{125}$.

122 = pabilo

123 = tendréis

124 El "Conde Claros" (Don Claros de Montalbán) fue el protagonista de un popular romance de origen carolingio. La melodía asociada a esta composición fue muy frecuentada por los vihuelistas, puesto que se han conservado diversas versiones para este instrumento (Mudarra, Pisador, Narváez, Valderrábano) [DíAz, Luis: "Evolución tradicional de un romance carolingio: "El Conde Claros"”, Cuadernos de investigación filológica, 4 (1978), pp. 57-72]. Es posible que así le apodaran a Martí Ponç, a quien se refiere en la rúbrica.

125 En valenciano/catalán fer la garagara = hacer demostración de lisonja [Diccionari catalá-castellá- llatí-francés-italiá, vol. 1. Barcelona, Imprenta de Joseph Torner, 1839, pp. 332, 1014]. 
No es malo mi tañer,

65 que dezís, para dançar, pues a vos haze baylar al son que yo quiero hazer.

Pues mi música no es dina ${ }^{126}$ de ser vos su oydor,

70 aquél ora que os afina, : $\quad$ hazed Bayla Catalina, yo seré su tañedor.

[127v] Y d'este arte oyréys lo vuestro de mi tañer,

75 y podreysme comprehender hasta donde comprehendéys.

A Dios pongo por testigo, si en nada burlo yo, que de quanto hago y digo,

80 vuestra fue la culpa, amigo, vuestra fue, que mía no.

\section{[14]}

[A, ff. 127v-128v / B, ff. 168v-169v / C, ff. 160r-161r].

Respuesta de don Joan Fernández a don Luis del Milán, en la qual se toca cómo lo avían hechado de casa del obispo de Sogorbe, y de un consonante falso que pone en las coplas y, al fin, de un hijo suyo que llevava como paje detrás ${ }^{127}$.

1 Soys el mayor trobador de liviano más pesado, y soys quien avéys hallado el arte de arte menor.

5 Coplones con tales pies no me vengan más delante, aprended qu'es consonante, pues que vos no lo sabés ${ }^{128}$.

[128r] D'aquesta mesa obispal,

10 que a vos os hecharon d'ella, no comen todos en ella,

que no es mesa de hospital.

126 = digna.

127 B (rúbrica): "Importunado, Joan Fernández le responde".

$C$ (rúbrica): "Don Luys Milán hizo unas coplas sobre dezir que comía y bevía más de lo que fuera menester en la mesa del obispo de Sogorbe, qu'él solía de comer, y ya no comía allí. Respuesta, porque aquel día traýa tras sí un mancebo muy desnudo, y ahun querían dezir que era su hijo".

128 = sabéis. 
De templado como assor ${ }^{129}$, vernéys ${ }^{130}$ según soys de presa,

15 a la mano de la mesa, y aun del aparador.

Creedme, no traygáys más tras vos el paje d'espuelas; almoaçe las vihuelas,

20 no burle de vos detrás.

Preguntele: ¿es tu maestro, que te aveza de dançar?

Fue tan san Pedro en negar, que juró que no era vuestro.

25 Corriose tanto el vellaco porque lo quise saber, que dixo: ¿cuyo ha de ser moço desnudo y tan flaco?

Sirvo al amo más cruel

30 que nunca se vio jamás. ¿Por qué te quexas, si vas muy mejor vestido qu'él?

[128v] Vuestro hijo dizen qu'es; sea, mas no creo yo

35 que tan desnudo nació como con vos le traés ${ }^{131}$.

Dizen que dize su madre, viendo que va tan desnudo: En mentir ${ }^{132}$ y en ser agudo,

40 todo es tal como su padre.

[15]

[A, ff. 128v-129r].

Réplica de don Luis del Milán en la qual apoda a don Joan a uno de Alicante, y repréndele de trobar tan suelto en las burlas.

129 = azor.

130 = vendréis.

131 = traéis.

$132 B, C$ : "vestir". 
1 Dezí1 ${ }^{133}$, señor, ¿no’s corréys

de tener tal desempacho, que revesáys como enpacho lo que trobáys y coméys?

5 Vuestro trobar se despacha, a según correros veo, en postas como correo picado de mi almoaça.

[129r] Pero sus vaya delante,

10 pues en el talle y turquesa, a Joan Fernandis de Mesa ${ }^{134}$ pareçéys, el de Alicante.

Ser vuestro deudo es manzilla, mas devéys de perdonalle,

15 pues qu'en todo tenéys talle de galán de fuera villa.

[16]

[A, ff. 129r-130r / B, ff. 155v-157v / C, ff. 161v-163r].

Respuesta de don Joan Fernández, en la qual nota a don Luis de los malos consonantes, y responde al apodo; y juntamente dize que aquellas coplas, su tío don Luis Milán, el loco ${ }^{135}$, se las debe ayudar a hazer; y por que se entienda de qual don Luis habla, porque ay otro primo suyo ${ }^{136}$, declárase $e^{137}$.

1 No gastéys más coplas mías, que las vuestras no las gasto, con un primor, el más basto, qu'e visto en todos mis días.

5 ¿Cómo no acudistes antes con este remedio luego, como con palo de çiego, por no errar los consonantes?

$133=$ decid

134 Posiblemente se trate de Joan Fernández de Mesa i Rocamora, caballero natural de Alicante, quien testó el 16 de marzo de 1552. No obstante, también podría ser Joan Fernández de Mesa i French, tío del anterior [Finestrat, Barón de: Nobiliario Alicantino. Alicante, Instituto de Estudios Alicantinos, 1983, pp. 133-135].

135 El noble Lluís del Milà i Llançol (†1548), llamado "el enfermo" por su enfermedad mental, fue el séptimo señor de Massalavés. Tuvo al menos tres hijos varones con Violant Eixarch: Pere -quien heredó el título-, Joan y Lluís.

136 Lluís del Milà i Eixarch $(* 1506 ? ; \dagger 1559)$ fue hijo del anterior.

137 B (rúbrica): "Don Luys, en unas coplas, llama a don Joan Fernández, Joan Fernández de Mesa, que es un cavallero que bive en Alicante, y respóndele don Joan”.

C (rúbrica): "Coplas a respuesta de unas que don Luys le hizo diziendo sobre lo de la mesa del obispo, qu'era Joan Fernández de Mesa del obispo ( $\mathrm{sic}$ ) de Alicante; y en aquella sazón dieron travesas unas fustas de Alger en Alicante; y tócale de no sé qué de la potencia y tanbién que respondió las mismas palabras en los consonantes; y havía un pie que dezía almoaçan".

Las coplas del vihuelista citadas en las rúbricas de $B$ y $C$ son el poema $\mathrm{n}^{\circ} 15$, no incluidos en estas fuentes. 
[129v] Tomando la forma y traça

10 de mis pies, cosa tan clara, ¿quién el consonante errara d'aquel pie de l'almoaça?

Almohazarse podría, porque pie tan suzio y frío,

15 antes me cortara el mío que ponelle en copla ${ }^{138}$ mía.

Veros, sobre ser mal diestro, tan malquisto, es cosa estraña, que ninguno os desengaña

20 sino yo, por ser tan vuestro.

Con todo, os hago correr fortuna, mas no qu'espante, hasta dar en Alicante, como las fustas de Alger ${ }^{139}$.

25 De verle enbuelto conmigo, a Joan Fernandis le pesa, y a vos, que no soys de mesa, del señor obispo, digo.

Acá se tiene por cierto

30 que os hechó, no hay que dudar, la mesa como la mar, por tener no sé qué muerto

[130r] No siendo hombre que ayuna, ¿por qué tenéys, que os apoca,

35 tantas mesas en la boca, y en la posada ninguna? Si tan mal os va de sillas, ya qu'en pie no debe ser, sentado podéys comer

40 como biuda en las rodillas.

138 C: "cosa".

139 Durante el reinado de Carlos v fueron frecuentes los ataques piratas de Barbarroja a la costa sur del reino de Valencia. Las expediciones partían de Argel y solían utilizar fustas, una suerte de pequeñas galeras. 
Otro don Luis, señor,

dizen qu'es con vos, sin duda;

si es el padre el que os ayuda,

el hijo fuera mejor.

45 Esta trinidad juntada, si con tres personas lucho, aunqu'el uno ${ }^{140}$ tengo en mucho, los otros no tengo en nada.

Tiene quebradas las alas

50 y el pico aquesta dolençia, qu'enfadáys toda Valencia de leer coplas tan malas.

Que si no acabáys con esto, creed como creéys en Dios,

55 que daré quexa de vos a la Justicia muy presto.

[17]

[A, ff. 130v-132v].

[130v] Réplica de don Luis del Milán, en la qual representa el entremés de Adán y Eva que se haze en Valencia el día del Sacramento ${ }^{141}$; y va descubriendo un secreto que dize averlo sabido del obispo de Sogorbe; y es que un cavallero muy viejo y no muy rico ${ }^{142}$ tenía una amiga hermosa, y era fama que don Joan mantenía la casa; y más descubre que la dicha dama tenía sin ellos otro Adán moço para sus deleytes ${ }^{143}$.

140 B, C: "hijo".

141 Este entremés, también llamado misterio (misteri) en Valencia, era uno de los que se representaba y cantaba en la lengua autóctona durante la procesión del Corpus Christi. Son los personajes que intervienen Adán, Eva, Dios, la Serpiente (Diablo), la Muerte y el Ángel, que aparece sólo al final para dar castigo a los dos primeros. Una edición de texto y música, procedente de un manuscrito del siglo XVII, puede encontrarse en RUIZ De LiHoRY, José: La música en Valencia. Diccionario biográfico y crítico. Valencia, Establecimiento tipográfico, 1903, pp. 107-120.

142 A juzgar por el texto del poema, se trata de Antoni Vilaragut. El tronco principal de la familia Vilaragut poseía el señorío de Olocau.

143 En El Cortesano, Jerònima Beneyto, esposa de Juan Fernández, da referencias de la existencia de esta composición: "Yo creo que será a casa de don Antón Vilaragut, que por lo que allí aze y dize le hizo don Luys Milán una obra donde le haze en ella Adán y a doña Antona Vilaragut y de Heredia Eva”. [D, f. BIIr]. 
1 No's paresca cosa nueva de vos la que dicho me an, y es que ogaño ${ }^{144}$ os darán el entremés de Adán y Eva.

5 L'Ángel será don Antón, pero no, que no es de Dios, que la Eva es de los dos por carnal disposición.

\section{[131r]Por cierto, mossén Thomás ${ }^{145}$}

10 todo esto va urdiendo; los jurados ${ }^{146}$, sonriyendo, le otorgaron esto y más.

Cierto, buena obra es, todos salirán a veros

15 por calle de Cavalleros ${ }^{147}$, don Joan hecho entremés.

Perdonadme del consejo, pues es bueno, al pareçer a rratos podéys hazer

20 él y vos l'ángel bermejo.

Quando don Antón será el Ángel del entremés, diros ha que sudarés ${ }^{148}$ y vos a él que toserá.

25 Si él queda y vos os vays, toserá en vuestra ausencia, pues sanáys de tal dolencia por el hambre que matáys.

Y quedando vos, ya veys,

30 si será todo sudar, pues os hazen bien pagar un bocado que coméys.

144 A: "ogano".

145 Seguramente se trata de mosén Tomàs Ripoll, presbítero capellán de la administración municipal valenciana en 1535 , un puesto que llevaba anejo el de capellà de les roques, responsable organizativo de la procesión del Corpus Christi [Archivo Histórico Municipal de Valencia, O-65, ff. 30r, 38r].

146 Los jurados (jurats), en número de seis -dos caballeros y cuatro ciudadanos-, formaban el núcleo del Consell Secret, órgano ejecutivo de la administración de la ciudad.

147 Céntrica calle valenciana por donde discurre la procesión de Corpus Christi inmeditamente tras su salida por la puerta de los Apóstoles, situada sobre el antiguo decumanus maximus romano y donde se concentraban gran número de casas nobiliarias. 148 = sudaréis. 


\section{[131v] Como por una malsana,} mançana, quiero dezir,

35 os quisistes destruyr vos y vuestra carne humana.

El Diablo es don Antón, que no es el ángel bueno, pues os veis un damasçeno ${ }^{149}$

40 llorando [e]n el Vall de Ebrón ${ }^{150}$.

Dama y cieno soys los dos, y es la dama vuestra Eva, y es el çieno esa cueva qu'ella y él abita, y vos.

45 Es l'Ebrón val de sudor, dond'estáys, por Satanás, $y$ en sudor de vuestra faz, viviréys por ruyseñor.

Veo grande inconveniente,

50 que no sé cómo será qu'en los dos no se hallará ángel y percuçiente.

Percuçiente ha de ser con la espada en la mano ${ }^{151}$,

55 y vosotros days de llano, según vuestro pareçer.

[132r] Otro inconviniente ay, otro que os dará mayor afán: ya no os quiere por Adán

60 vuestra Eva, sino a otro.

Su Adán más moço es, que apenas tiene boço; es tan moço para moço como vos para vejez.

149 A: "damaçeno".

150 El valle de Hebrón, en Palestina, también se le llamaba el "Valle de las Lágrimas" porque se decía que allí fue donde Adán lloró durante cien años la muerte de su hijo Abel a manos de su hermano Caín.

151 En el misteri, el ángel porta una espada con la que golpea a Adán y Eva como castigo. 
65 No sé cómo ser podrá, mossén Thomás se arrepiente; no ay ángel percuciente, y el Adán, ¿quién lo será?

Cosas dize de su boca,

70 que no sabe qué hazer; yo l'e dado un pareçer : $\quad$ con que puede yr la roca ${ }^{152}$.

Ya me [ha] dicho que le plaze con qu'el moço sea Adán,

75 y haga el Ángel el Joan, pues lo hizo y siempre haze.

Don Antonio, muy contento, : $\quad$ será la Sierpe, pues lo es, y harase el entremés

80 el día del Sacramento.

[132v]Es la Muerte d'este chiste la figura de los dos, del Vilaragut y vos, que no ay cosa más triste.

85 Miedo he que nos espantéys el plazer y alegría d'aquel tan alegre día, pues que nunca le tenéys.

Casos sé por un obispo

90 de vos, don Joan travieso, que si entran en proçeso no's valdrá vuestro arçobispo.

A Dios siempre rogaré, pues trobáys para perderos

95 de donayrosos senderos, libera nos Domine.

152 En Valencia, tradicionalmente se llaman rocas (roques) a los carros dedicados a santos u otros asuntos religiosos que salen en la procesión del Corpus Christi. Sobre algunos de ellos antiguamente tenían lugar, además, las representaciones de algunos misteris, como era el caso del de Adán y Eva. 


\section{[18]}

[A, ff. 132v-133v / B, ff. 162r-163r / C, ff. 163v-165r].

Respuesta de don Joan Fernández a don Luis del Milán, en la qual torna a tocar lo que dixo en la otra respuesta pasada, y es que su tío o sobrino le ayudan a hazer las coplas; y agora dize que no, sino que le dan de comer, y tócale del yr mal vestido y senzillo en invierno ${ }^{153}$.

1 [133r] Estas coplas que me dan, de asco que tenéys d'ellas, creo no devéys leellas; por eso van quales van.

5 Vuestros coplones, de buenos juzgados por trobadores, los postreros son mejores, por ser los que valen menos.

Provad, señor, otra cosa,

10 pues sabéys menos hazer en metro, que no en meter, devéys daros a la prosa.

De los don Luyses dos, el moço en otro socorre ${ }^{154}$,

15 mas en coplas ya se corre si le dizen qu'es con vos.

Antes de vuestro trobar, está diziendo con tino: más os valiera, sobrino,

20 de las coplas no curar.

Él saldrá tan mal maestro como yo de mi dotrina, aunque no de medicina, pues soy gran físico vuestro.

$153 B$ (rúbrica): "Responde a otras coplas que don Luys le hizo, en las quales encaxó un romance que dize: Moro viejo, moro viejo".

$C$ (rúbrica): "Respuesta de unas coplas que don Luys le haze en que encaxa un romance que dize moro viejo; y él quiere quexarse a la Justicia d'este pleyto si más le importunara".

$154 B, C$ (verso 14): "el padre en otro os socorre". 
$25[133 v]$ Y no de dolencia poca, qu'era humor para matar, si no hiziera revesar tales coplas por la boca.

No es de calor, en verdad,

30 que vos bien devéys sentillo, de andar vestido senzillo todo el mal es frialdad.

No es el cuero tan de malla, que no se sienta de açotes

35 sino el vuestro, que de motes tiene callos y no calla.

Si trobáys por no callar, no lo devéys d'escrevir, que a tantos haréys reir,

40 que alguno os hará llorar.

Dexaos d'escuros latines, y avisoos qu'el viejo moro, más quiere esperar un toro qu'esperar coplas ruýnes.

45 De su parte se os protesta, si más trobáys d'esta vez, os emplaza ante'l juez, que allí os dará la respuesta.

[19]

[A, ff. $134 \mathrm{r} / B$, ff. $154 \mathrm{v}]$.

[134r] Réplica de don Luis del Milán a don Joan Fernández sobre una cuera que llevava con ${ }^{155}$ una escarçela grande ${ }^{156}$.

1 No quiero caer ni cayo, y cayo bien en lo que es, qu'esa cuera que traés ${ }^{157}$ me pareçe cuera y sayo.

5 Señor, avéys de saber, porque soys de tal manera, que de dentro ni de fuera no's podemos entender.

155 A: "co".

156 B (rúbrica): "Don Luys a don Joan Fernández".

157 = traéis. 


\section{[20]}

[A, ff. 134r-135r / B, ff. 155r-155v / $C$, ff. 167v-168r (faltan los versos 21-30)].

Respuesta de don Joan Fernández a don Luis del Milán, en la qual muestra que quanto don Luis dize de los vestidos es por que le dé don Joan alguna ropa suya ${ }^{158}$.

1 Quien mi çetrería siente, para las aves de buelo pongo carne en el siñuelo; para pescar otra gente

5 puse sayo en el ansuelo. [134v] Vos, qu'en el sayo picastes, de la galla avéys quedado pescado, como pescado, pues que no's escarmentastes

10 de mí en el trobar pasado.

Pasemos como entre hermanos d'estas coplas que hazés ${ }^{159}$; Milán, más que milanés, ¿cómo con tam buenas manos,

15 hazéys tan ruýnes pies?

$\mathrm{Si}$ os pareçe gran desastre mi sayo, y contra natura, como el talle es ${ }^{160}$ la hechura, y bien pudo errar mi sastre,

20 como vos la compostura.

Mas quieros ${ }^{161}$ dar a [e]ntender que habláys mal informado d'Indias do ${ }^{162}$ no havéys estado, qu'el vestir va del tañer

25 mil leguas diferençiado.

Con lo qu'este sayo cuesta, de brocado se hiziera, [135r] y a menos costa le diera, que no coplas por respuesta

30 si la copla lo valiera.

158 B (rúbrica): "Don Joan Fernández a don Luys Milán”.

$C$ (rúbrica): "Respuesta a una copla que hizo don Luys Milán a un sayo naranjado que él traýa".

159 = hacéis.

$160 B, C:$ : "y".

161 = quiéroos.

162 = donde. 
$[A$, ff. $135 \mathrm{r}-135 \mathrm{v} / B$, ff. $149 \mathrm{r}-149 \mathrm{v} / D$, f. [CviIr $]]$.

Réplica de don Luis del Milán a don Joan Fernández; y diola al duque ${ }^{163}$; y el duque la dio al governador don Luis Ferrer ${ }^{164}$ para que la diese a don Joan; y ansí el governador se la embió. Tócale en ella aver dexado la ropa de grana y la azul y aver tomado lo verde ${ }^{165}$.

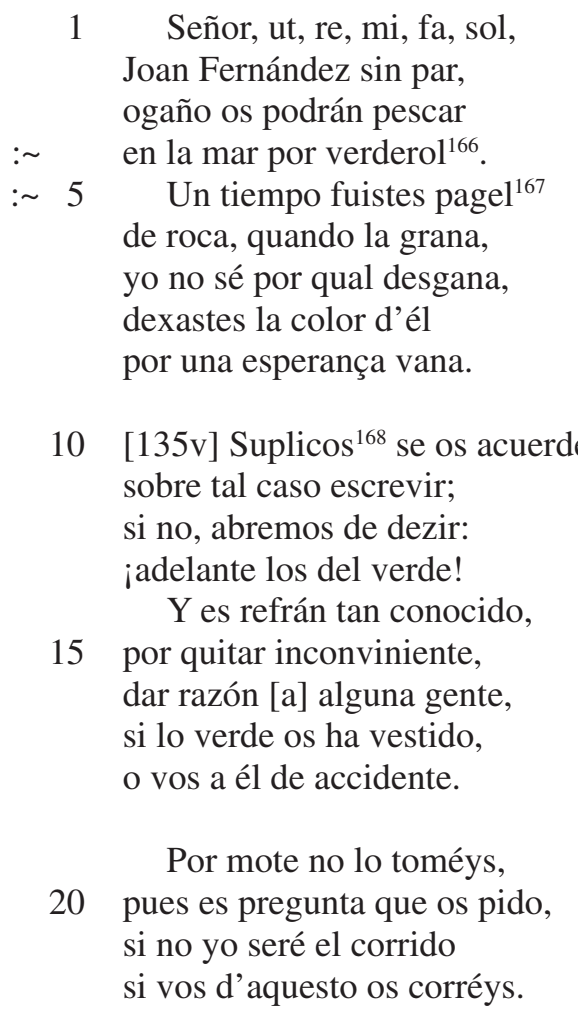

163 El duque de Calabria don Fernando de Aragón (*Andria, 1488; †Valencia, 1550), virrey del reino de Valencia durante los años 1526-1550.

164 Lluís Ferrer fue gobernador de Valencia, cargo público de rango superior cuyo inmediato superior jerárquico era el propio virrey. Era hijo de Jaume Francesc Ferrer, quien previamente había renunciado a su cargo de lugarteniente de gobernador a favor de Lluís, y estaba casado con Castellana de Borja, citada en $D$, f. cIr.

$165 B$ (rúbrica): "Algunas obras de burlas, y estas primeras passó con un cavallero amigo suyo, el qual le hizo estas coplas, y embiolas al duque de Calabria".

$D$ (intervención de Luis Milán): "Y tratando muy gran verdad, digo que Joan Fernández vino al juego de la pelota muy canicular en los días caniculares, en cuerpo, sin capa, vestido de monte o de mote, con un sayo y calças y montera de paño y un jubón algodonado de fustán; todo tan verde, que no vino nada maduro, con tan grandes calores como hazía, que no se podía bivir con tafetanes. Y diziéndome don Francisco Fenollet: «¿Qué risa es ésta que se ha levantado tan grande?» Yo le dije: «Del cielo viene lo que por castigo se haze. ¿No véys qual ha venido nuestro amigo, un enero en juliol, hecho un verderol?» Y por esto le hize estas tres coplas, que si comiençan con puntos de música fue por burlar de la suya, pues burla de la de todos; y recíbalo con paciencia." $[D$, f. CVIIv].

166 Verderón, serviola o pez limón. Pez de color amarillento ligeramente verdoso de la familia del jurel.

167 Pagel, breca o besuguete. Pez de color rojo por arriba y rosáceo por los costados.

168 = suplícoos. 
Perdone la ocasión

que lo verde me a dado,

: 25 que por verderol pescado,

entre platos y un limón,

al duque os he presentado.

\section{[22]}

[A, ff. 135v-136v / B, ff. 149v-151r / C, ff. 154v-155v].

Respuesta de don Joan Fernández a don Luis del Milán, y va dirigida al governador don Luis Ferrer, porqu'él l'embió las coplas por mandado del duque de Calabria ${ }^{169}$.

1 [136r] Señor don Luis Ferrer, quien las coplas me a traýdo, como apenas l'e [e]ntendido. no puedo bien responder.

5 Pregunté: ¿por quién se dan las coplas no me dirés ${ }^{170}$ ?

Dixo: en ellas lo verés ${ }^{171}$, por don Luis del Milán.

Como hay tres ${ }^{172}$ no sé quál es.

10 El re, mi, fa, sol declara quál es de los dos señores, con puntos que son mayores ${ }^{173}$ que si fuesen por la cara.

Bien dezís, mas qué se pierde

15 declarar lo qu'está escuro, que si es él no me aseguro ${ }^{174}$, pues que m'ha llamado verde, que no me llame maduro.

Con todo, ha sido maliçia

20 que coplas tan de reýr, no devieran de venir a manos de la Justiçia.

169 B (rúbrica): “Don Luys Ferrer, governador, embió las coplas a don Joan Fernández de parte de don Luys Milán. Responde don Joan".

$C$ (rúbrica): "Don Luys Milà hizo dos coplas diziendo que un tiempo pareçía pajel [...] una ropa de grana que traýa, y que aora por otra verde que trae paresce verderol, las quales copla[s] presentolas al duque de Calabria, y el duque las dio a don Luys Ferrer para que las enviasse a Liria a cuenta que don Joan les respondiesse lo que se sigue." Las coplas a que se refiere son las del poema ${ }^{\circ} 21$, no incluido en $C$.

$170=$ diréis

171 = veréis.

172 B, C: "dos"

173 B, C: "peores".

$174 B, C$ (verso 16): "siendo d'él no'stoy seguro". 


\author{
Aunque mejor se açertara \\ si, como es governador, \\ 25 fuera desgovernador, \\ para que desgovernara \\ de coplas al trobador. \\ Coplas baxas de pagel, \\ no son de tal cavallero, \\ 30 por donde su despensero \\ las ha hechas, que no él. \\ Él le tiene tan ocioso \\ de no dalle en qué servir, \\ que sin tener qué dezir \\ 35 haze coplas de donoso \\ por no perder l'escrevir. ${ }^{175}$ \\ [136v] Yo, a mi pareçer, diría \\ que, aunque gusto del presente, \\ como el duque es eccelente ${ }^{176}$, \\ 40 más gusto de quien lo embía. \\ Con todo, si a mí me diera \\ un presente tan ligero, \\ yo preciara primero \\ más un higo, aunque fuera \\ 45 de mano del tesorero. ${ }^{177}$
}

\title{
[23]
}

[A, ff. 136v-137r / B, f. 160r / D, f. DiIIr].

Réplica de don Luis del Milán, en la qual nota a don Joan Fernández porque un día en verano fue sin capa a l'yglesia ${ }^{178}$ mayor $^{179}$.

175 La estrofa que comprende los versos 28-36 aparece en $A$ después de la correspondiente a los versos 37-45, aunque en el margen izquierdo aparece en números romanos la ordenación estrófica que he reflejado en mi edición, que coincide también con la de $B$.

176 El duque de Calabria, como virrey, recibía el tratamiento de Su Excelencia.

177 La respuesta de Juan Fernández al poema n² 21 en $D$ es totalmente diferente a las que transmiten el resto de fuentes:

"Señor, re, mi, fa, sol, la, / respondo al ut, re, mi, fa, sol / vuestro, galán. / De vos se quexa mi águila / que la hizo verderol / vuestro milán. / En el buelo se ha mostrado / vuestro milán como encaxa / en amor. / Quien tras águila ha bolado, / si por verderol se abaxa, / es pescador.

Vos hazéys lo que hazer suele / el milán en su bolar, / por bivir sano; / que por muy alto que buele / l'avemos visto abaxar / por un liviano. / Esse milán que tenéys, / d'altibajo es su gran buelo / en llano y sierra. / Cantad lo que vos hazéys, / que buelo hasta el cielo / y quedo en tierra.

Las damas os desengañan, / que no’s quieren mirar más / si las miráys. / Pues vuestras cosas engañan, / todo es Pedro, por demás, / si festejáys. / Dizen que os han descubierto, / que soys muy desamorado / en amores, / Qu'el primer día soys muerto / y el tercer ressuscitado / sin dolores. [D, DiR-Div].

178 A: "yglesi".

179 B (rúbrica): "Don Luys a don Joan Fernández". 
1 [137r] Dicho me an, señor don Joan, que se toma residencia, en la ciudad de Valençia, del oficio de galán.

5 Monsoriu ${ }^{180}$ me a [a]visado, ${ }^{181}$ qu'en cuerpo y desabrochado, contrahazéys al mallorquín; dezidme qué's vuestro fin, que de risa m'e finado.

\section{[24]}

[A, ff. 137r-138r / $B$, ff. 160v-161v / $C$, ff. 156r-157r].

Respuesta de don Joan Fernández a don Luis del Milán, en la qual encaxa el romançe de Durandarte ${ }^{182}$ buelto a don Luis ${ }^{183}$.

1 Por la risa y gran plazer que days en lo que dezís, quiero, si no os desservís, deziros mi pareçer,

5 aunque no me lo pedís.

Dar consejo es, por demás, al mancebo el hombre viejo, y por eso me aparejo a pagar, pues queréys más : 10 çinco sueldos ${ }^{184}$ qu'el consejo.

$D$ (intervención de Luis Milán): "Ítem, más salió el señor Joan Fernández por la yglesia mayor, sin capa y con el sayo desabrochado, para oýr la onzena, que es la missa de los perezosos. Y fue tan mortal este peccado, que nadie lo quiso absolver sino el obispo de Fez de vuestra Excellencia, que perdona de todos los peccados. Y porque supo que no peccó en día de fiesta, ni por mostrar su gentil cuerpo, sino por remedar a un cavallero mallorquín, que quiso poner este mal uso en Valencia. Y fue tan reýdo qu'el señor Joan no hosó más bolver a pecar en este peccado. Y por esto fue de las damas perdonado. Pero no se me fue sin copla, y es ésta." [D, f. DIIIr].

180 Cabe la posibilidad de que se trate del caballero valenciano Gaspar de Monsoriu, quien en 1551 fue elegido para tratar el problema de la defensa de la costa ante los ataques berberiscos [GiméNEz CHORNET, Vicente: "La representatividad política en la Valencia foral", Estudis, 18 (1993), p. 22].

$181 D$ (verso 5): "El pueblo está alborotado".

182 Precisamente Luis Milán incluyó en El Maestro una composición propia para canto y vihuela con texto basado en este romance anónimo [Milán, Luis: Libro de música de vihuela de mano intitulado 'El maestro', ed. de Francisco Roa. Madrid, Sociedad de la vihuela, 2008, pp. 88-89]. También incluyó una glosa poética a este romance en $D$, ff. HIIr-HIIIIv.

183 B (rúbrica): "Responde don Joan".

C (rúbrica): "Otras suy<as> en que le scrive un romance que empieça Duro en l'arte, duro en l'arte".

184 El sueldo (sou) era unidad de cuenta monetaria en el reino de Valencia equivalente a la veinteava parte de una libra (lliura) y a doce dineros (diners). 
[137v] Si la vihuela holvidáys ${ }^{185}$, y trobáys, y componéys, tomáys lo que no sabéys, y lo que sabéys dexáys,

15 y así, señor, os perdéys.

Dexaos de trobar, en fin, y no os metáys en tal trançe, que un podenco os dará alcançe; y pues no sabéys latín,

20 quieros ${ }^{186}$ trobar en $^{187}$ romançe.

Romançe.

Duro en l'arte, duro en l'arte, duro trobador forçado, acordársete devía, d'aquel coloquio ${ }^{188}$ passado,

25 quando em baxas invenciones, ocupavas $^{189}$ tu cuydado.

Yo publiqué la respuesta ${ }^{190}$ en campo por tí aplazado, quando yo era tu amigo,

30 de tu tañer namorado.

El tañer desconoçido, por mal trobar as trocado. Palabras son lisongeras, por mí creýdas de grado,

35 de que quedo mal conmigo [138r] de averlo muy mal pensado, ${ }^{191}$ que si yo mudança hize, mal consejo lo a causado. Y este mal recaudo ha sido

40 estando vos desterrado, mas si d'esta vez no's creo, que muera desesperado.

185 C: "apeáys".

186 = quiéroos.

$187 \mathrm{~B}, \mathrm{C}$ : "un".

188 B: "culoquio".

189 B, C: "publicavas".

190 A: "repuesta".

$191 C$ : falta el verso 36. 
Villançico y desecha.

Mejor que os quadra el romance,

os prometo de glosalle

45 si no me rogáys que calle.

Rogar y aun prometer

si lo dexo de glosar,

que no's avéys de curar ${ }^{192}$

de trobar ni componer.

50 Y pues sabéys el tañer mexor que nadie açertalle, tañé ${ }^{193}$, si queréys que calle. ${ }^{194}$

[25]

[A, ff. 138r-138v / B, ff. 164-165r].

Respuesta de don Luis del Milán a don Joan Fernández, en la qual le nota de una ropa morada que se avía hecho ${ }^{195}$.

1 [138v] Una ropa avéys sacado de muy deversas colores; si son de vuestros amores, yo os doy por disculpado.

5 Yo no atino vuestro pelo si es natural o acidente; dezidme si soys pariente de aquel arco $^{196}$ del çielo.

¿Es morada invención ${ }^{197}$,

10 o intención namorada, o es condiçión mudada ${ }^{198}$, buelta en camaleón?

Camaleón soys, mi señor, esto cierto deve ser,

15 qu'en mudar de nuevo amor, os vestistes del color que se viste la muger.

192 B, C: "trobar".

193 = tañed.

194 La respuesta de Juan Fernández en $D$ es totalmente diferente:

"Dicho me han, señor don Luys / que os han hecho juez de gala; / buena será para mala / si juzgáys como servís.

Rey fue mal aconsejado; / creo que vos lo aconsejastes; / a vos y a él ha engañado; / a él, porque a vos la [ha] dado; / y a vos, porque lo tomastes." [D, f. Diiiv].

195 B (rúbrica): "Copla de don Luys a don Joan Fernández". Tras el verso 8: "Del mesmo a don Joan Fernández a una ropa morada que traýa".

196 B: "arco azul".

197 B: "intención".

198 B: "morada". 


\section{[26]}

\section{[A, f. 138v-139r].}

Respuesta de Joan Fernandes a don Luis del Milán.

1 [139r] Muchos están aburridos de vos, que soys pesadilla; yo más que toda Castilla, pues roéys vos mis vestidos

5 mucho más que la polilla.

Esto es ya cosa muy loca, mas çertificos ${ }^{199}$, Milán, qu'estoy por huýr de afán, por ataparos la boca

10 con uno, como con pan.

\section{[27]}

[A, f. 139r / D, f. Dviv].

Réplica de don Luis del Milán a don Joan Fernández, porque avía dançado con un cavallero llamado don Eneas, y avía hecho la dama ${ }^{200}$.

1 Donosa está vuestra fama, bueno vays, señor don Joan; ${ }^{201}$ yo's tenía por galán $\mathrm{y}$ anme dicho que soys dama.

5 Bien podéys cantar de oy más aquella triste sonada de Dido, la desdichada: "Eneas, ¿por qué te vas, y me dexas tam burlada?"

[28]

$[A$, f. $139 \mathrm{v}]$.

[139v] Respuesta de don Joan Fernández a don Luis del Milán.

199 = certifícoos.

200 D (intervención de Luis Milán): "Bien se os acuerda, quando fuystes dama de don Eneas Ladrón, que os sacó a dançar en el Real, estando en serau la reyna, mi señora, y su excellencia; y vos no le negastes vuestro cuerpo, que parecistes la reyna Dido que yva dançando con su Eneas troyano, como vos con el vuestro, que parescía Eneas gitano, que por parescernos vos tan feo para dama como él para galán, le apodamos a «camafeo» y a vos a «dama fea». Pues fue el caso tan feo, que no hallamos con qué salvaros sino con Lope de Rueda, que lo quesistes contrahazer, por dar plazer, a costa vuestra, como esta copla muestra." $[D$, DVIv-DVIIr]

201 D (versos 1-2): “Bueno vays, señor don Joan! / Puesto estáys en buena fama:”. 
1 Sienpre en achaque de trama, os ponéys en tanto afán que, a ser buytrera, el milán estuviera como en cama.

Pero con todo os acuerdo, por vuestro bien y reposo, que si os picáys de donoso, tan necio soys para cuerdo, quan frío para gracioso. ${ }^{202}$

\section{[29]}

[A, ff. 139v-140r / B, ff. 163r-163v (continúa con el poema nº 1 )].

Réplica de don Luis del Milán a don Joan Fernández a modo de romance y diálogo, en la qual toca a don Joan porque siempre estava en Liria ${ }^{203} 204$.

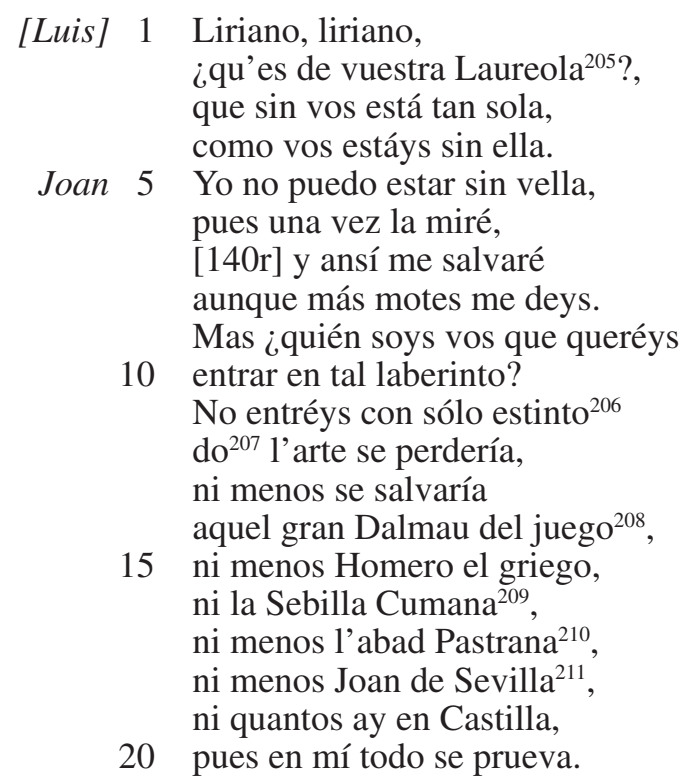

202 La respuesta de Juan Fernández al poema $\mathrm{n}^{\circ} 27$ en $D$ es totalmente diferente al que transmite $A$ :

“ ¡Cantó l'alva la perdiz! / Más le valiera dormir, / pues dançastes con Betriz / para darnos que reyr. / Gilot lo supo después, / que con su Betriz dançastes, / pues de su casa llevastes / a la vuestra el mal francés / que a don Francisco pegastes.” [ $D$, f. Dviv].

203 Llíria, población situada a $25 \mathrm{~km}$ al noroeste de Valencia.

204 B (rúbrica): "Romance de don Luys Milán".

205 Leriano y Laureola son los protagonistas de la novela sentimental Cárcel de amor de Diego de San Pedro (Sevilla, 1492).

206 = instinto.

207 = donde.

208 Este personaje aparece también en El Cortesano: “A Dalmau me semejáys, que figura por punto mostráys”. [D, f. gIvr].

209 La Sibila Cumana o Sibila de Cumas, así llamada porque la mitología le atribuye su residencia en esta ciudad de la Campania italiana, fue considerada durante la antigüedad como la más relevante de las sibilas.

210 Se trata del músico Pedro de Pastrana $(† 1561 p)$, quien fue en Valencia maestro de capilla del duque de Calabria y abad del monasterio cisterciense de Sant Bernat de Rascanya, reconvertido por los duques en jerónimo bajo la advocación de san Miguel de los Reyes para albergar su panteón.

211 Uno de los bufones de la corte valenciana de los duques de Calabria. También aparece en El Cortesano. [D, ff. Kvr, Kvv, RviIIv]. 


\section{[30]}

[A, ff. 140r-140v].

Respuesta de Joan Fernández a don Luis del Milán.
: 1 ¡O qué lirio tan donoso!, que trahe nuevas de abril, pero por Pasqua es gentil, mas yo atalle no oso.
5 Direos una cosa sola, y podeisme bien creer: que con tal lirio, a mi ver, no ganaréys l'aureola, ni se dexa mereçer.
$10[140 v]$ Cosa es ésta, por mi vida, digna de ser bien notada: que siempre days ensalada en principio de comida.
¿Quién diablos rebolviera
15 a Dalmau y a Homero el griego, : $\quad$ y a Joan de Sevilla luego, para que d'asco muriera
: $\quad$ si en ella'stuviera Diego? ${ }^{212}$.

[31]

[A, f. 140v].

Réplica de don Luis del Milán a don Joan Fernández porque llevava una cuera de alimanisco.

1 D'esta vez yo me arisco, del Fenollet es la empresa, alemán de alimanisco, como de turco turquesa,

5 os ha hecho don Françisco.

D'él he oýdo que os avéys, señor, vestido de manteles una cuera; yo le dije que si era

10 por la mesa o qué avía sido. 


\section{[32]}

[A, f. 141r].

[141r] Respuesta de don Joan Fernández a don Luis del Milán.

1 Muero por desengañaros, y nunca os desengañáys, que tan lexos d'esto estáys, que nunca podéys trobaros

5 por más coplas que trobáys. Mi vestir es cosa para reýr, mas así, me ayude Dios, que más se ríen de vos

10 en lo que days que dezir.

[33]

[A, ff. 141r-143r].

A esta sazón llegó una carta de Barçelona para don Joan Fernández, en la qual le davan aviso de ciertas nuevas. $Y$ don Luis dixo qu'estavan mal hordenadas y peor entendidas y, a rruegos ${ }^{213}$ de çiertas damas, hizo esta interpretaçión.

1 De la carta plazer huve, de las palabras, pesar, que lo que dize la carta [141v] no lo puedo interpretar.

5 De un desorden me a venido, no de vuestro hordenar, qu'e perdido la memoria, y tanbién l'imaginar. Yo soy el que tengo culpa,

10 que no es ella de culpar, pues viene tan conçertada, que pudiera concertar españoles y françeses, que no ay más que hablar.

15 Reçebila con plazer, y saliome, a pesar que unas damas la riñeron por hazerme gran pesar. Buscava en ella nuevas, 20 y no las pude hallar.

213 A: "rrugos". 
Dizen que viene tan corta que no llega al pensar. Púseme entr'ella y ellas por hazella allegar.

25 Llegose a los oýdos, d'allí no pudo pasar.

Dixe qu'era sólo escrita, para mi considerar, como una horden nueva

30 [142r] de çifras allende'l mar, que yo sólo las entiendo y no las puedo aclarar; y puesto que lo pudiera, no quise, por hazellas rabiar.

35 Mandome la una d'ellas, la qu'en mí puede mandar, que la carta declarase, si se puede declarar. Començé de santiguarme,

40 y a la carta santiguar, y enpeçaron mil relámpagos, risadas de gran tronar, de verme hazer ademanes para demonios sacar.

45 Díxeles que estoy nublado de un melarchico ${ }^{214}$ pesar, por que de mi entendimiento pudiese un sol mostrar, que viesen clara la carta

50 ser de nuestro navegar. Después que la entendieron, riyeron a más andar de ver dos navigaleros bergantines sin haldar ${ }^{215}$,

55 embiados para nuevas, y sin nuevas allegar. $[142 \mathrm{v}]$ Las nuevas de nuestro rey las hizo asosegar, mas no tanto que dexasen

60 de reýr, a mi pesar:

De los trigos que os vienen

214 Seguramente melarchico = melancólico $($ de melarchía = melarquía = melancolía $)$. y la paja.

215 Posiblemente proviene de halda = arpillera grande con que se envuelven y empacan algunos géneros, como el algodón 
provensales ${ }^{216}$ por la mar,

dizen que con ellos viene

mal françés para matar,

65 y vosotros, de golosos,

no hazéys sino tragar.

Escrevís de profeçías;

no las puedo declarar

porque ya se fue el Mesías

70 a los çielos a reynar.

Díxeles que d'este paso

no podía más passar, para dar passo a dezillas, más me yva que jurar,

75 qu'entre vos y yo, y ella, ellas no pueden entrar.

De los muertos, por rincón quisiéronme arrinconar.

¿Cómo es? ¿Y quién los mata?

80 ¿Quién son? ¿Y de qué lugar?

¿Escrevís de una burla, que a llegado [a] afrentar a nuestro rey tan de veras?

[143r] ¿Cómo esso de burlar?

85 ¿De dónde lo sabéys vos, que pudiese allegar

esta burla, que burlase

con quien no ossan burlar?

Catalanes pensamientos

90 lo deven interpetrar, que son muy fríos farautes a sabor de paladar.

De la burla me dixeron qué nuevas podría dar;

95 aquí he quedado mudo, que no puedo más hablar.

Rogaréys a santa Engracia que nos quiera ingraçiar a vos, y a mí, y a la carta,

100 para en gracia tornar. 


\section{[34]}

[A, ff. 143r-145r].

Respuesta de don Joan Fernández, y açertose que, un día antes, don Luis salió a departir una brega de negros, y una moça de una ventana envistiolo con un caldero d'agua suzia.

1 [143v] Vuesa merçed se aperçiba que yo me quiero vengar en el suzio mandilete, pues qu'en vos no ay lugar,

5 por ser galán tan marcado qu'en la corte no ay su par en apasiguar quistiones ${ }^{217}$, en armas, y em pelear. Salistes como caudillo

10 por vuestro valor mostrar, y çierto se pareçiera si el agua diera lugar. Donde'l señor pone'l pie, atrás no le a de tornar.

15 Diziendo va: ¡aparta, aparta!, que yo no'stoy de vagar, y por vida de mi dama que a todos mande matar. Es la gente malcriada;

20 no se quieren apartar hasta ver el mandilete, que bastó [a] amedrentar. Harto más qu'el cavallero, pues no lo dexan pasar,

25 quanto más prisa se dava, [144r] menos le hazen lugar, hasta que de una ventana, quiriéndole ayudar, con grandes caçuelas d'agua

30 le pensaron ahogar. Lançadas tenéys, amigo, mas son de agua de fregar. Diéronlas de una ventana, que de çerca no ay lugar, 
35 tanto no puedan caçuelas

que le hagan retirar.

Lo qu'el cavallero dize, razones de lo contar:

¡Borrachos! ¡Cuerpo de Dios!

40 ¿No podéys considerar quién soy, y de dónde vengo, de qué sangre y qué solar?

Conocido le an todos en el tono del hablar.

45 Mira, Nero de Tarpeya ${ }^{218}$, a Milán todo mojar.

$¡ \mathrm{O}$, sobrino Valdovinos ${ }^{219}$ ! ¿Quién os truxo a tal lugar, con negros y gente baxa

50 que no saben estimar $[144 \mathrm{v}]$ el valor de la persona que vos soléys demostrar? Entre damas os escuchan, mucho más en el justar,

55 de noches y sin lanterna, por el preçio ganar. ¿Quién os ha tan mal parado, qu'estáys más para llorar que no para ser llorado,

60 si bien miráys el lugar? Gran cuenta le dava un negro, el caso empieça a contar, mas él, de muy enojado, no le quisiera escuchar;

65 escuchárale de grado si tuviera que mudar. Mas, tornando al mandilete, pues él me lo ha de pagar, de afrentado y de escozido,

70 no le quiere acompañar, ni quiere más socorrelle si le falta qué hablar.

218 "Mira Nero de Tarpeya / a Roma cómo se ardía" son los versos iniciales de un romance viejo [DiAz-MAs, Paloma: "Sobre la fortuna del romance 'Mira Nero de Tarpeya'", en José L. Melena (ed.), Symbolae Ludovico Mitxelena septuagenario oblatae. Vitoria, Universidad del País Vasco, 1985, pp. 795-798].

219 Baldovinos es un personaje de la épica francesa, procedente de la leyenda de Ogier li Danois, que pasó a los romances castellanos. En El Maestro se incluye una versión de Sospirástes, Baldovinos [Milán, Luis: Libro de música de vihuela..., op. cit., pp. 90-91]. 
Bueno queda el cavallero que con él solía armar.

75 La primer razón qu'entona

[145r] quando viene a visitar:

¡Contra el guante! ¡Viene armado!

No a gana de pelear.

A favor del mandilete

80 enpieça de razonar, subiendo por la escalera, qu'en la sala quiere entrar:

Tal mandilete, señora, bien parece de Milán.

[35]

[A, ff. 145r-146r / B, ff. 165r-166v / $C$, ff. 165v-167r].

Don Joan Fernández escrive estas coplas a miçer Martín Ponçe pidiéndole consejo en estos negocios d'él y de don Luis del Milán 220.

1 Si el buen consejo aprovecha, de $v u<$ e $>$ sa merçed le pido, que sin él no he querido echarme como quien s'echa

5 tras un virote perdido.

Mas haré que se le acuerde al que me haze tal obra, qu'es tan perdido que sobra, [145v] que ya quien tras él se pierde,

10 no es perdido si se cobra.

No sé cómo me defienda d'aqueste pleyto en que ando, que yo justicia demando de quien sienpre esta contienda

15 la comiença y va llorando.

De lexos quiero tomar el agua d'este proçeso, qu'este trobador travieso, con coplas sin encarar

20 me despara y haze avieso.

220 B (rúbrica): "No responde don Joan Fernández, sino que pide consejo y justicia a un cavallero amigo suyo".

$C$ (rúbrica): "Pide consejo a Martín Ponç, porque el otro le enxite [incite?] en algunas coplas, de cómo se ha de regir con la Justicia si el otro le replica más". 
¿Qué coloquio tan reýdo fue'l que desparó primero! Pujadas fue'l mensajero, que por no avelle traýdo

25 diera un pozo de dinero.

$\mathrm{Y}$ aquellas Turcas maneras, y el romançe liriano, qué lirio para verano, qu'en este tiempo, de veras,

30 de frescas yelan la mano.

[146r] Y sin mí mil otros muele, con coplas que media basta, que potros de mala casta, la costa que comen duele,

35 de tinta y papel que gasta.

Sobre hazelle más regalos que a la persona de un rey, en fin, de no tener ley, con coplas me da de palos,

40 que basta [a] matar un buey.

Son tales, si Dios me vala, las coplas con que me afrenta, que ay más primor a mi cuenta en hazer una ${ }^{221} \tan$ mala,

45 qu'en hazer buenas çinquenta.

D'aquesta cuenta que os doy, como señor y letrado,

a Dios y al mundo la he dado hasta [a] él, que harto estoy

50 d'avelle desengañado.

Qu'en trobar no s'entremeta, esto por bien que le quiero, porqu'es gentil cavallero, pero no de la gineta,

55 que bien le pesa al overo. 
[36]

[A, f. 146v].

[146v] Escrive don Joan Fernández a don Luis del Milán en boca de Martín Ponçe.

1 Lo que de vos me lastima, y a todos inportuna,

es, quebrando tanta prima ${ }^{222}$, no rasgar copla ninguna.

[37]

[A, f. 146v].

Respuesta de don Luis del Milán a Martín Ponçe.

1 Dos Ponçes, y no Pilatos, casados vi en una fiesta; fue cosa tan manifiesta como lo fueron sus tratos.

5 Máscara fue que hazían que a momios contrahazían. Y fue tam bien contrahecha, que pusieron en sospecha a mil ojos que los veýan.

Fin

Recibido: 16/11/2010

Aceptado: 30/11/2010

222 La cuerda más aguda de la vihuela. 